\title{
LAS PERSONAS ANCIANAS EN LA JURISPRUDENCIA ARGENTINA. ¿HACIA UN DERECHO DE LA ANCIANIDAD?
}

\author{
Aída Kemelmajer de Carlucci *
}

RESUMEN: La ancianidad no debe ser visualizada como un proceso solo biológico; por el contrario, debe ser encarada desde el marco general de las políticas públicas y la legislación, en ese sentido la autora plantea la existencia de una ética y un derecho de la ancianidad, presentando datos mundiales y un panorama acabado del tratamiento jurisprudencial en Argentina. El envejecimiento progresivo de la población mundial plantea la problemática de conservar a los ancianos en el seno de la sociedad, encontrándoles el lugar que por su dignidad y por sus aptitudes deben ocupar para bien de la comunidad. Los legisladores y jueces tienen una gran tarea por delante, ya que si bien las fuentes normativas internacionales vigentes contemplan disposiciones, estas suelen ser demasiado programáticas y flexibles, y han tenido escasa proyección en el derecho interno.

Palabras clave: Derecho de la ancianidad, derechos humanos, ancianos, jurisprudencia argentina, Bioética.

ABSTRACT: Aging should not be analyzed as a mere biological process. By the contrary, it must be dealt with within the broader context of public policies and legislation. In this sense, the author assumes the existence of an ethic and a law which are specific to the elderly people. She provides global data and an overview of the judges' way to deal with the elderly in the framework of Argentinean Law. The fact that the population at large is increasingly older in most countries of the world brings about the need to protect them within their respective societies. The law must find them the place where they belong to, a place which they deserve due to both their dignity and their skills. Lawmakers and judges still have a lot to do because, even though the international legal sources have come to include some norms. These latter are said to be over flexible and programmatic and there is little hope for them to be turned into national law.

Key words: Elder law, Human Rights, elderly people, Argentinean caselaw, Bioethics.

Delante de las canas te levantarás y honrarás el rostro del anciano (Levitico).

"Las edades se pueden comparar con los vinos: así como no todos se avinagran por añejos, no toda edad se aceda por avanzada" (Cicerón).

\section{LÍMITES Y OBJETIVO DE ESTAS REFLEXIONES}

En todos los tiempos, la ancianidad ha sido objeto de profundas reflexiones desde la óptica de la filosofía, la sociología, la psicología social, etc. De ella se han preocupado

\footnotetext{
* Abogada, Doctora en Derecho. Profesora de las Universidades de Mendoza, Argentina.
} 
pensadores de la talla de Cicerón ${ }^{1}$, Bobbio ${ }^{2}$, Simone de Beauvoir ${ }^{3}$, y tantos otros. También la poética se ha referido reiteradamente a ella por lo que no pudo pasar inadvertida para José Hernández, autor de la obra argentina más representativa de este género literario (el Martín Fierro ${ }^{4}$ ), ni para Sor Juana Inés de la Cruz, una de las primeras mujeres que expresó la voz femenina en América Latina ${ }^{5}$. En los últimos años, la Bioética ha proporcionado nuevos enfoques ${ }^{6}$.

${ }^{1}$ CICERÓn (1946) p. 161. Cicerón escribe esta obra en el año 44 a. C. cuando tenía sesenta y dos años. No es una obra jurídica; solo buscaba consolar y solazar a su amigo Pomponio Atico a quien le entristecía envejecer. En este diálogo imaginario, Catón el Censor, que por entonces tenía 84 años y cumplía sus funciones públicas y domésticas, enseña a los jóvenes Escipión y Lelio a llevar con resignación los achaques de la vejez. Los viejos se lamentan de estar excluidos del manejo de los negocios, de perder las fuerzas, de no poder gozar de los placeres de la vida, y de tener la muerte cerca. Cicerón da respuesta a esas quejas. En este diálogo se lee, además de la frase colocada al comienzo de estas líneas (ubicada en el capítulo XVIII), otras igualmente conocidas: "Los que no tienen auxilios dentro de sí mismos para vivir contentos y felices, a estos todas las edades le son pesadas, pero los que buscan todos los bienes dentro de sí mismos, no les puede parecer mal ninguno de aquellos que trae consigo la necesidad de la naturaleza" (capítulo II); "Es miserable la vejez que necesita de apologías. No pueden las canas y las arrugas dar de repente autoridad: la vida pasada, si ha sido honesta, es la que logra los más copiosos frutos de ella" (capítulo XVIII). "El tiempo de la vida, aunque corto, bastante largo es para vivir bien y honestamente; y si pasare más adelante, no lo debemos sentir más que sienten los labradores la venida del verano y el otoño después de la primavera. La primavera se compara con la juventud que manifiesta los venideros frutos, el demás tiempo es a propósito para segar y para recogerlo. El fruto de la vejez es la copia y la memoria de los bienes que antes se ha adquirido y se ha de contar entre los bienes todo cuanto lleva de suyo la naturaleza" (capítulo XIX). "Nadie en mi muerte me honre con su llanto, que andaré vivo en la boca de los hombres" (cita a Ennio, capítulo XX). Otras tantas y bellas citas son reproducidas por BASTIDAS (2004).

2 Bоввіо (1997). Bobbio escribe la primera parte de esta obra cuando tenía ochenta y cinco, y la segunda, dos años más tarde. Recuerda que los dos maestros de su generación, Benedetto Crocce (1866-1952) y Luigi Einaudi (1847-1961), admirados por su laboriosa vejez, murieron el primero a los ochenta y seis años y el segundo a los ochenta y siete. Pese a su visión pesimista, deja un gran mensaje: "Las satisfacciones más duraderas de mi vida no provinieron de los frutos de mi trabajo, pese a los honores, premios y distinciones públicas recibidos, agradecidos aunque no ambicionados ni solicitados. Provinieron de mi vida de relación, de los maestros que me educaron, de las personas que amé y me amaron, de cuanto siempre han estado a mi lado y ahora me acompañan en el última vuelta del camino. El tiempo del viejo es el pasado. El pasado revive en la memoria. El gran patrimonio del viejo está en el maravilloso mundo de la memoria, fuente inagotable de reflexiones sobre nosotros mismos, sobre el universo donde hemos vivido, sobre las personas y acontecimientos que a lo largo del camino nos llamaron la atención” (p. 72).

${ }^{3}$ DE BEAUVOIR (1989).

${ }^{4}$ Verso 1162 :

"La cigüeña cuando es vieja

Pierde la vista, y procuran ayudarle en su edá madura

Todas sus hijas pequeñas

Apriendan de las cigüeñas

Este ejemplo de ternura”.

5 Soneto 148:

“... y aunque llega la muerte presurosa

Y tu fragante vida se te aleja

No sientas el morir tan bella y moza;

Mira que la experiencia te aconseja

Que es fortuna morirte siendo hermosa

Y no ver el ultraje de ser vieja"

${ }^{6}$ Casado (inédito). Agradezco a María Casado, Directora del Observatorio de Bioética y Derecho de la Universidad de Barcelona, haberme permitido la lectura de su valioso artículo. 
En la realidad social, son muchas las organizaciones nacionales e internacionales que trabajan sobre el envejecimiento y la vejez ${ }^{7}$.

Desde la juridicidad, el tema ha sido abordado en jornadas organizadas por universidades de distintos países ${ }^{8}$; no es de extrañar, pues, que los académicos también hayan destinado importantes reflexiones al fenómeno9. Anticipo que el rol del Derecho no es menor puesto que "a las normas corresponde determinar las condiciones sociales y valorativas que deben ser respetadas en relación con los ancianos" 10 .

Dentro de esta vastedad, el propósito de este trabajo, en homenaje a nuestra querida Olga Mesa, es muy limitado: solo intento verificar si la jurisprudencia de la República Argentina se mueve o no al vaivén de los "nuevos vientos" en la materia, es decir, los vientos de los derechos humanos.

\section{PRELIMINARES}

Se ha dicho que para cumplir plenamente su destino biológico, todo ciclo vital humano debe pasar por cinco crisis fundamentales: el nacimiento, la madurez, la reproducción, la vejez y la muerte; por eso, ninguna cultura humana ignora por completo estos períodos críticos. La diferencia reside en el grado de intensidad con que afronta a cada uno de ellos ${ }^{11}$. Así, el hombre del paleolítico tenía muy pocas posibilidades de llegar a la ancianidad; se lo impedían las carencias alimenticias, la enfermedad, la caza, la falta de protección frente a los rigores climáticos, etc; en efecto, los fragmentos de esqueletos más antiguos que se han encontrado pertenecen a individuos que no sobrepasaban los treinta años; en consecuencia, en aquel entonces, la vejez no debe haber sido uno de los problemas más difíciles de afrontar ${ }^{12}$.

\section{ETIMOLOGÍA}

Al parecer, la palabra anciano nació en la primera mitad del siglo XIII; es un derivado de un vocablo de la lengua romance (anzi), que significa antes. Se trata, pues, de un concepto que señala la relación del ser humano con el tiempo; la persona

\footnotetext{
7 Ver un listado de estos organismos en TOMASELlo (2002).

8 Compulsar Villagrasa (2002) (Este libro contiene una decena de artículos de diferentes autores y un anexo en el que se reproduce le legislación autonómica española); ALONSO et al. (2004) (La obra reproduce más de veinte artículos de prestigiosos autores sobre diversos temas).

${ }^{9}$ La Academia Nacional de Derecho de Bs. As. ha hecho aportes a través de Morello (2002) p. 232; el trabajo se reproduce en LL 2002-E-1210 y en MORELLO (2003) pp. 151 y ss y Risolía, quien fuera mi predecesor en el sillón "Aristóbulo del Valle" aclara en su comunicación que el tema lo había abordado, una década antes, en el $2^{\circ}$ Congreso Argentino de Geriatría y Gerontología, en septiembre de 1979. La Real Academia de Madrid ha recogido las reflexiones de José María CASTÁN (2001) p. 339.

10 DABOVE (1996) p. 49.

${ }^{11}$ Hoebel, citado por Dabove (2002) p. 122.

12 Dabove (2002) p. 124.
} 
anciana es la que cuenta con un "antes, un pasado mayoritario, que respalda lo poco que vendrá" 13 .

\section{CONCEPTO}

Obviamente, en la conceptualización de la ancianidad tiene gran relevancia el dato cronológico; es difícil separar la ancianidad del paso de la edad cronológica. En biología, la senectud consiste en el conjunto de procesos biológicos que condicionan el deterioro de células, tejidos órganos ${ }^{14}$. ¿A qué edad se produce ese fenómeno? ¿A los sesenta, los setenta, los setenta y cinco?

No basta responder a esa pregunta; el problema es más complejo porque la ancianidad no constituye solo un proceso biológico; es también un concepto histórico y cultural. Aparte de que existen enfermedades que aceleran el envejecimiento de una persona, "la misma edad cronológica no significa lo mismo ni en términos biológicos ni culturales en todas las sociedades, razas, sexos, ni en todas las personas; no se envejece por igual en el campo que en la ciudad, con una alimentación adecuada o no, llevando una vida sedentaria o activa, fumando y bebiendo, etc." ${ }^{15}$.

En suma, existe un cierto acuerdo en que la noción de ancianidad no es exclusivamente biológica, y aun desde esa perspectiva no se pueden fijar límites precisos ${ }^{16}$.

A los efectos estadísticos, en algunos casos se toma la vejez a partir de los 65 años, edad que se hace coincidir con el inicio de la jubilación para la población económicamente activa; la Organización Mundial de la Salud, en cambio, ha establecido la línea en los 75 años. En realidad, el límite se irá extendiendo a medida que aumente la longevidad de la persona humana merced, en gran parte, a los progresos de la ciencia.

\section{LA ANCIANIDAD EN EL SIGLO XXI. ALGUNOS DATOS CUANTITATIVOS}

El siglo XXI ha sido denominado el "siglo del envejecimiento demográfico". El tema afecta a todo el mundo y se trata de un envejecimiento generalizado, sin precedentes en la historia de la humanidad ${ }^{17}$. Se habla de la "revolución blanca", expresión que describe el aumento del número de las personas de edad en la población mundial ${ }^{18}$, del "envejecimiento del envejecimiento", locución que significa que aumenta el número de personas de más de sesenta y cinco años que sobreviven pasados los setenta y cinco $^{19}$; de la "revolución de las canas", de "la madurez de la humanidad", etc., frases que no son retóricas,

\footnotetext{
13 Dabove (2002) p. 103.

14 SALAS (1999) p. 2.

15 Morelli (1999) p. 33.

16 Gonem de Gandolfo (1996) p. 83.

17 TOMASELLO (2002).

18 URIARTE (1991) p. 7.

19 De Palma (2002) p. 135.
} 
sino que tienen una base estadística inequívoca. De acuerdo con algunos datos estadísticos, en setenta y cinco años la población total se habrá triplicado (hoy es de 6.000.000.000), la de los ancianos se habrá sextuplicado, y la de las personas de más de 80 años se habrá decuplicado ${ }^{20}$. En América Latina, los países que están a la vanguardia de este proceso de envejecimiento demográfico son Argentina, Uruguay y Cuba. En el primero, la población mayor de 65 años alcanza el $13.5 \%$ y se estima que en el 2030 llegará al $17.5 \%{ }^{21}$.

\section{LA REACCIÓN DE LOS GRUPOS SOCIALES FRENTE A LA ANCIANIDAD}

En todos los tiempos, las sociedades han reaccionado frente a la ancianidad de diferentes maneras ${ }^{22}$; las pautas culturales, económicas, sociales, geográficas, históricas, etc. son condicionantes por demás significativos. Como categoría social, la vejez presenta un abanico que va desde la inutilidad, hasta el máximo prestigio. Desde el Matusalén bíblico y Sara pariendo en su senectud, en toda la geografía del mundo y de la humanidad "hay ancianos ilustres y sabios, conocidos y desconocidos; en Argentina, el libertador San Martín luce anciano y reposado en su exilio voluntario de Boulogne Sur Mer"; "la historia muestra muchos senectistas que cambiaron el destino de las naciones: De Gasperi, Adenauer, Schuman, Roosevelt, Monnet son prueba ilevantable en el azaroso siglo XX, con inevitables y dolorosos eclipses, como el del mariscal Petain"23. "Pero junto a estos ancianos ilustres, están los ancianos desconocidos, víctima de las estadísticas y de procesos de ajuste económico que resuelven cortar por lo más débil”24.

Cada época ha debido resolver dos cuestiones fundamentales en relación con la vejez: por un lado, saber qué lugar otorgar al anciano en el seno de su sociedad; por el otro, elaborar algún concepto que la identifique. "Toda la historia de la vejez ha sido un largo y doloroso ensayo de respuesta; ensayo múltiple, discontinuo y variado, aunque también ambiguo y contradictorio" 25 .

De cualquier modo, en grandes líneas, puede afirmarse que "en las sociedades tradicionales estáticas que evolucionan lentamente, el viejo encierra en sí el patrimonio cultural de la comunidad; el viejo sabe por experiencia lo que los otros no saben aún y necesitan aprender de él. Por el contrario, en las sociedades evolucionadas, el cambio cada vez más rápido, tanto de las costumbre como de las artes, ha trastrocado la relación entre quien sabe y quien no sabe. El viejo se convierte crecientemente en quien no sabe

20 Travieso (1995). Datos similares surgen del informe del Instituto Nacional de Estadísticas y Censos de Argentina transcriptos por CADOCHE (2002) p. 93 y ss.

21 Wilde (2005c) p. 891 y ss; CADOCHE (2002) p. 94.

22 La obra de Simone de Beauvoir contiene una extensa y completa descripción de la situación de los ancianos en los diferentes países y épocas, sintetizada por los autores posteriores. Ver WILDE (2005a) p. 147.

23 Morello (2002).

24 Travieso (1995).

25 DABOve (2000) p. 1022. 
con respecto a los jóvenes que saben, y saben, entre otras cosas, porque tienen más facilidades para el aprendizaje". "Contribuye a aumentar la marginación del viejo un fenómeno que es de todos los tiempos: el envejecimiento cultural, que acompaña tanto al biológico como al social; el viejo tiende a permanecer fiel al sistema de principios o valores aprendidos e interiorizados en la edad que está entre la juventud y la madurez, o incluso solo a los hábitos que, una vez formados, resulta penoso desarraigar. Y como el mundo que lo rodea cambia, tiende a dar un juicio negativo sobre lo nuevo, únicamente porque ya no lo entiende ni le apetece esforzarse por comprenderlo. Cuanto más firmes mantiene los puntos de referencia de su universo cultural, más se aparta el viejo de su propia época" 26 . En el mismo sentido se ha dicho que "el vertiginoso avance de los conocimientos hace que la valoración de la ancianidad entre en crisis. La vejez ya no es fuente de verdad. La memoria del anciano ya no sirve porque sus conocimientos se tornan obsoletos con progresiva rapidez. Poco espacio queda para la comunicación intergeneracional al tiempo que se profundiza la sensación de aislamiento" 27.

Por otro lado, no puede ignorarse que actualmente las llamadas sociedades occidentales dan un valor superlativo al consumo, y "aunque se hable de los nuevos consumidores seniors y se hayan creado y comercializado algunas formas culturales y de ocio pensadas para la edad de oro (gran eufemismo), es evidente que la ancianidad coincide, en general, con una baja del poder adquisitivo, convirtiéndose esta circunstancia en otro factor de exclusión, lo que agrava su situación, pues es sabido que el aislamiento, la soledad, el no ejercitar las capacidades y la autonomía propia, generan más incapacidad y un envejecimiento mayor" 28 . En esta línea, se señala que, a menudo, las condiciones del anciano son más graves que las de otros grupos minusvalorados, como las mujeres y los niños, porque estos tienen mayores posibilidades de ser admitidos en las tareas productivas $^{29}$.

Tampoco debe olvidarse que, como describe Alfred Sauvy ${ }^{30}$, "el viejo puede ser indeseable por dos razones: por las cargas y molestias que ocasiona, y por la propiedad

\footnotetext{
26 BоввIO (1997) pp. 27 у 29.

27 DABOVE (2000) p. 1026.

28 CASADO (inédito).

29 Ciuro Caldani, Miguel A., Prólogo al libro de Dabove (2002) p. 19.

30 SAUVY, pp. 141 y sgtes., cit. por TRAVIESO (1995). Alfred Sauvy (Francia, 1898/1990) es el demógrafo, antropólogo e historiador de la economía a quien se atribuye haber acuñado la expresión "Tercer Mundo" (Tiers Monde); la usó en un artículo aparecido en L'Observateur el 14/8/1952 para referirse a las naciones jóvenes de Asia y África que al terminar la Segunda Guerra mundial comenzaban a independizarse de las potencias coloniales europeas. Vio en las aspiraciones de estos nuevos países algunas semejanzas con el "Tercer estado" de la Francia prerrevolucionaria, que en la asamblea nacional representaba al pueblo en contraste con los dos grupos minoritarios y privilegiados que integraban los clérigos y la nobleza ("Car enfin ce Tiers Monde ignoré, exploité, méprisé comme le Tiers-État, veut, lui aussi, être quelque chose"). Tras la liberación de Francia de la invasión nazi fue nombrado por De Gaulle Secretario General de la Familia y a la Población en abril de 1945, pero pronto abandonó las tareas políticas para dedicarse a la investigación. Entre 1947 y 1980, representó a Francia ante las Naciones Unidas en la Comisión de Estadística y de Población. Fue presidente de esta Comisión de 1951 hasta 1953. En el libro Costo y valor de la vida humana, Sauvy denuncia los criterios que se han tenido para juzgar la vida cuando se la considera apenas como un bien utilitario. El estudio de estos criterios hoy ha dado lugar a una nueva área del saber denominada antropología económica.
} 
de bienes raros o preciosos de los cuales priva a la población activa”. En los países subdesarrollados, la idea general no es "eliminar los viejos" pero sí separarlos de la vida activa para liberar los empleos; el viejo es un obstáculo para la plena ocupación y, por eso, es necesario una jubilación, lo más ínfima posible, para dejar libre el puesto de trabajo que requiere el joven; en otros términos, el viejo que trabaja es un indeseable del que hay que desembarazarse. Esta actitud se desentiende moralmente de sus consecuencias: según algunas investigaciones, la jubilación acelera la muerte de la persona que, por un método de exclusión social, reduce sus recursos y cambia bruscamente su vida. Desde esta perspectiva, jubilados y desocupados son comparables: "aunque el jubilado goza de otro tipo de prestigio social, en la realidad, parece ser un desocupado perpetuo hasta la muerte" 31 .

El problema presenta mayores dificultades en los países pobres; por un lado, por la débil infraestructura institucional para atender las necesidades del creciente número de ancianos; por el otro, porque la familia está sufriendo ajustes económicos que la colocan en marcos de difícil subsistencia en los que la solidaridad entre los miembros del grupo comienza a debilitarse.

A lo expuesto, algunos autores trialistas ${ }^{32}$ suman la especial situación de deterioro de la mujer anciana, manifestada en tres direcciones: en el plano de la realidad social, en el sistema normativo y en de los valores. En efecto "la mujer anciana actúa como sujeto pasivo y no como conductora de los fenómenos sociales; debe oír y no ser escuchada; con el paso del tiempo pierde sus referencias culturales, su estatus social y el control de su vida; pocas veces será capaz de llegar a acuerdos. La enfermedad, la disminución de sus ingresos, la soledad, la falta de vivienda, el desprecio de sus antiguos talentos y la marginación agudizan la situación”.

De cualquier modo, no debe creerse que "todo tiempo pasado fue mejor"; para muestra basta un botón: en mi país, no obstante el llamado que el preámbulo de la Constitución hace a "todos los hombres del mundo que quieran habitar el suelo argentino", la ley 817 de 1876 sobre inmigración y colonización incluía a los mayores de 60 años entre las personas que los capitanes de buque tenían expresamente prohibido transportar en calidad de inmigrantes, a no ser que se tratara de jefes de familia ${ }^{33}$.

\section{7. ¿HACIA UN DERECHO DE LA ANCIANIDAD?}

Los derechos de los ancianos se presentan dentro de una profunda dispersión normativa; por otro lado, a nivel jurisprudencial, se encuentran pocos fallos que contemplen la situación del anciano con visión integral.

Se ha sostenido que los derechos de la ancianidad sufren una doble capitis diminutio: de un lado, en el mejor de los casos, forman parte del grupo de derechos humanos económicos, sociales y culturales, de limitada eficacia; del otro, constituyen un grupo de

\footnotetext{
31 TraVieso (1995).

32 DABOVE (1996) p. 49.

33 Dato histórico recordado por URIARTE (1991) p. 13.
} 
derechos bastante novedoso, de reciente consagración, por lo que son objeto, en el mejor de los casos, de políticas sociales coyunturales y no de derechos subjetivos directamente operativos $^{34}$.

Frente a este panorama, en la República Argentina, algunos autores propician la creación de un "Derecho de la ancianidad", rama que debería desarrollar perspectivas transversales llamadas a enriquecer las ramas tradicionales (derecho civil, comercial, administrativo, penal) y desenvolver un derecho que supere los límites que aíslan y mutilan la situación del anciano ${ }^{35}$.

En algunos aspectos, la cuestión se asemeja al Derecho de Menores, rama con la que guardaría "correspondencia vital" 36 ; por eso, por ej., en el Derecho Procesal deben aumentarse los esfuerzos para escuchar debidamente a menores y ancianos, y en el Derecho de los consumidores debe advertirse que ancianos y menores son consumidores especiales. El paralelismo no significa identidad; así, se reconoce que la situación de los menores provoca más atención que la de los ancianos, y se sospecha que en el sistema capitalista esta diferencia puede deberse, en parte, a que "lo que se destina al menor es más inversión; en cambio, el esfuerzo a la protección del anciano es más consumo, sin correlativa inversión"; quizás esa también sea la causa por la cual la bibliografía ofrece un notable contraste entre el número y extensión de los estudios dedicados a los menores y a los ancianos ${ }^{37}$. En la misma tendencia, es decir, marcar el paralelismo pero señalar las diferencias, Simone de Beauvoir dice que el problema del negro es un problema de blancos y el de la mujer, un problema masculino; pero los negros pelean contra la opresión y la mujer lucha por conquistar la igualdad; en cambio, los viejos no tienen ningún arma, y su problema es un problema de los adultos activos que deciden acerca del papel que conviene conferir a los ancianos, según su propio interés práctico e ideológico"38.

Se acepte o no la creación de una nueva rama, hay cierto consenso en que la problemática de la ancianidad no debe ser visualizada como un proceso solo biológico; por el contrario, debe ser encarada desde el marco general del mundo político integrándola con las perspectivas de la política sanitaria, económica, científica, educacional, cultural, etc.

\footnotetext{
${ }^{34}$ DABOVe (2000) p. 1025.

35 Ciuro (1992) p. 35; (1995) p. 7; ver, también, Prólogo al libro de Danove (2002) p. 18; Dabove, (2000) p. 1020. En México, SALAS (1999) p. 6 y ss. El autor mexicano define el derecho de la senectud como el "conjunto de conocimientos, principios y normas relacionados con la situación de las personas de la tercera edad" (p. 9). Europa también viene publicando obras con la misma tónica integradora. En Italia, STANZIONE (1991); la obra contiene una decena de artículos que analizan la cuestión del anciano desde la perspectiva constitucional, civil, su autonomía contractual, temas de responsabilidad civil, etc; CARLEO, (1997); el libro reproduce una docena de artículos; FERRANDO, Gilda, "I diritti degli anziani tra famiglia e istituzioni”, en CENDON (2004) p. 1781. Para la situación en Francia y un estudio comparativo con el derecho norteamericano, ver MERCAT-BRUNS (2001).

36 El paralelismo entre Derecho de Menores y Derecho de los ancianos ha sido objeto de preocupación en Italia desde la perspectiva del Derecho Penal; ver Dogliotti, Máximo, "Il Diritti dell'anziano", en STANZIONE (1991) p. 49.

37 CASTÁN (2001) p. 340.

38 DE BEAUVOIR (1989) p. 108.
} 


\section{ANCIANOS Y DERECHOS HUMANOS}

"Apoyar a la juventud no debe significar arrojar todos los días viejos por la ventana" 39 . Por eso, al menos teóricamente, hay consenso en que el equilibrio de la sociedad descansa en el conjunto de sus miembros; consecuentemente, para conseguir la armonía hay que evitar generar procesos de exclusión, contrarios al respeto de los derechos humanos.

Los documentos internacionales que contienen disposiciones directa o indirectamente vinculadas al derecho de las personas de mayor edad son muy numerosos. Por ej., la Declaración Universal de los Derechos del Hombre de 1948 establece que toda persona, como miembro de la sociedad, tiene derecho a la seguridad social. El título XVI de la Declaración Americana de Derechos y Deberes Humanos de 1948 dice: “Toda persona tiene derecho a la seguridad social que le proteja contra las consecuencias de la desocupación, de la vejez y de la incapacidad que proveniente de cualquier otra causa ajena a su voluntad, la imposibilite física o mentalmente para obtener los medios de subsistencia”.

Con un criterio más amplio, la Declaración Universal de los Derechos Humanos establece: "Toda persona como miembro de la sociedad tiene derecho a la seguridad social y a obtener, mediante el esfuerzo nacional y la cooperación internacional, habida cuenta de la organización y los recursos de cada Estado, la satisfacción de los derechos económicos, sociales y culturales indispensables a su dignidad y al libre desarrollo de su personalidad" (art. 25). El Pacto de los Derechos Económicos, Sociales y Culturales de 1966 enumera los mismos parámetros normativos y remarca que el Estado se obliga a proveer los recursos necesarios "hasta el máximo de que disponga".

Más específicamente, el Protocolo adicional a la Convención Americana sobre Derechos Humanos en materia de derechos económicos, sociales y culturales suscripto el 17/11/1988 dice: Art. 17: "Toda persona tiene derecho a protección especial durante su ancianidad. En tal sentido, los Estados partes se comprometen a adoptar de manera progresiva las medidas necesarias a fin de llevar este derecho a la práctica, y en particular: a) proporcionar instalaciones adecuadas, así como alimentación, atención médica especializada a las personas de edad avanzada que carezcan de ella y no se encuentren en condiciones de proporcionársela por sí mismo; b) ejecutar programas laborales específicos destinados a conceder a los ancianos la posibilidad de realizar una actividad productiva adecuada a sus capacidades respetando su vocación o deseos; c) estimular la formación de organizaciones sociales destinadas a mejorar la calidad de vida de los ancianos".

Aceptado este punto de partida, hay que concluir que la sociedad tiene la obligación de priorizar la prevención y el cuidado de la calidad de vida de los ancianos, manteniendo su autonomía, tan ligada a la dignidad de la persona.

Lamentablemente, la realidad es otra. Las fuentes normativas internacionales vigentes suelen ser demasiado programáticas y flexibles, con escasa proyección en el derecho interno. Así, por ej., el Plan internacional de Viena sobre el envejecimiento, aprobado en 1982, no es más que un conjunto de recomendaciones que cada Estado puede

39 TRAVIESO (1995). 
asumir o desechar a su arbitrio. Lo mismo sucede con la Declaración de Cartagena de Indias de 1992 sobre políticas integrales para las personas mayores en el área iberoamericana ${ }^{40}$.

\section{LA ACTUACIÓN DE LOS ORGANISMOS INTERNACIONALES}

Si los derechos de los ancianos deben ser analizados a la luz de los derechos humanos, es normal que los organismos internacionales se ocupen de ellos.

La ONU está actuando desde la década del 50. En 1992 la Asamblea General aprobó un plan de acción internacional sobre el envejecimiento con metas para el año 2001. El año 1999 se declaró año internacional de las personas de edad.

En marzo de 1995, se celebró la Conferencia de Copenhague. El párrafo 26 y el compromiso 2 de la Declaración surgida de este encuentro dicen: "Nosotros, los representantes del gobierno... crearemos acciones... que mejoren la posibilidad de que las personas ancianas obtengan un mejor estilo de vida... desarrollaremos y mejoraremos políticas que aseguren a todas las personas una protección económica, social y cultural adecuadas durante... viudez, discapacidad o edad avanzada". Por otra parte, el programa de acción de Copenhague declara que "deben ser puestos esfuerzos particulares para proteger a las personas ancianas, incluyendo aquellos con disparidad a través de... el mejoramiento de la situación de las personas ancianas en casos particulares donde ellos no gocen de apoyo familiar... asegurando que las personas ancianas puedan satisfacer sus necesidades humanas básicas a través del acceso a servicios y seguridad social... fortaleciendo medidas... que aseguren a los trabajadores jubilados no caer en la pobreza".

\section{ANCIANOS Y PRINCIPIOS DE BIOÉTICA}

La Bioética estudia e intenta dar solución a muchos problemas generados por la edad avanzada ligada a la dependencia, tales como:

a) La evidencia que la medicina curativa tiene límites, y que hay procesos que aunque no puedan ser curados requieren ser atendidos a los fines de poder disfrutar la mayor calidad de vida posible.

b) La verificación que las sumas necesarias para el cuidado de la salud pueden crecer ilimitadamente; de hecho, en algunos países occidentales aumentan más deprisa que el producto interno bruto. Pues bien, frente a recursos escasos, a la hora de adoptar decisiones, el gestor de los intereses públicos debe tomar en consideración, en difícil y delicado equilibrio, por un lado, la garantía de una atención digna y no discriminatoria por razones de edad ni de pronóstico, y por el otro, el resto de las necesidades de la población. Se trata de opciones claramente políticas que deben estar precedidas por un debate realmente democrático. Estas opciones tienen una dimensión ética ya que deci-

40 DABOve (2000) p. 1025. 
den sobre la prioridad del gasto que se realiza y, consecuentemente, sobre la salud y la calidad de vida de los individuos.

c) La necesidad de políticas tendientes a la adopción de decisiones respetuosas de la voluntad libre y suficientemente informada del anciano.

Esta voluntad rige, especialmente, en cuanto a la elección de su hábitat. El aumento de los años de vida repercute en el número de personas con dependencia física y psíquica; cuando las personas se hacen mayores e incapaces de valerse por sí mismas, se acude a dos alternativas: o se las cuida en el domicilio, o se las lleva a una institución especializada; ambas situaciones plantean problemas. El ingreso al geriátrico implica especiales situaciones jurídicas ${ }^{41}$. Por su parte, los cuidados a domicilio requieren cuidadores profesionales; además, frecuentemente se omite una cuestión muy importante, cual es, que cuando el anciano dependiente queda en casa (especialmente si se añade una discapacidad o una demencia senil) quien lo cuida es la hija; esa realidad tiene un gran significado e impacto en la vida intelectual y profesional de las mujeres, que no solo asumen la crianza de sus hijos, sino el cuidado de los ancianos.

La autonomía es igualmente importante para poder decidir, por uno mismo, en todo cuanto concierne a la salud: contratar seguros que le garanticen el acceso a todas las prestaciones necesarias; establecer disposiciones anticipadamente, para cuando ya uno no pueda hacerlo, tema que supone hablar de testamentos vitales, designación de representantes e, incluso, de eutanasia.

El difícil tema del consentimiento informado se agudiza tratándose de ancianos. En efecto, si bien la ancianidad no debe identificarse con enfermedad, pueden presentarse disminuciones en las facultades psíquicas y/o físicas que impidan que el sujeto pueda tomar decisiones de modo autónomo ${ }^{42}$.

\section{ANCIANOS Y DERECHO CONSTITUCIONAL ARGENTINO}

Los ancianos no estaban mencionados en el texto originario de la Constitución argentina sancionado en 1853. Mucha agua pasó debajo del puente hasta la reforma de 1994 que entre las facultades del Congreso introdujo la de "legislar y promover medidas de acción positiva que garanticen la igualdad real de oportunidades y de trato y el pleno goce de los derechos reconocidos por esta Constitución y los Tratados Internacionales vigentes sobre Derechos Humanos, en particular respecto de los niños, las mujeres, los ancianos y las personas con discapacidad" (art. 75 inc. 23) ${ }^{43}$.

Pese a la fortaleza de la formulación, se ha dicho que "el reconocimiento de los derechos de la ancianidad resulta extremadamente débil en la Constitución Nacional y solo se cuenta con alguna referencia específica en un artículo que cuenta con escasa

\footnotetext{
41 Di Tullio (2003) p. 108; en la misma obra, en p. 177 ver GONEM MaChello De Gandolfo (2003).

42 Dibárbora (2002) p. 479 y ss.

43 Me he referido a las acciones positivas en mis artículos. Kemelmajer (1997) p. 16; Kemelmajer (1998).
} 
proyección inmediata, el art. 75 inc 23, y el inc 22 referido a la vigencia de los tratados y pactos internacionales" 44 .

Entre el texto originario y el de 1994, la reforma de 1957 estableció que "el Estado otorgará los beneficios de la seguridad social que tendrá carácter de integral e irrenunciable. En especial, la ley establecerá.... jubilaciones y pensiones móviles" (art. 14 bis de la Constitución argentina) ${ }^{45}$.

La fórmula española es mucho más completa; en efecto, el art. 50 dispone: "Los poderes públicos garantizarán mediante pensiones adecuadas y periódicamente actualizadas, la suficiencia económica de los ciudadanos durante la tercera edad. Asimismo, y con independencia de las obligaciones familiares, promoverán su bienestar mediante un sistema de servicios sociales que atenderán sus problemas específicos de salud, vivienda, cultura y ocio". Sin embargo, las quejas también aparecen en este país europeo; en efecto, un sector de la doctrina hispana sostiene que se trata de un derecho "especialmente débil”, por ser programático ${ }^{46}$.

En la Argentina, aun antes de la reforma de 1957, un sector doctrinal consideró que los derechos de la ancianidad tenían rango constitucional por ser uno de los derechos implícitos mencionados en el art. 33 de la CN que dispone: "Las declaraciones, derechos y garantías que enumera la Constitución no serán entendidas como negación de otros derechos y garantías no enumerados, pero que nacen del principio de la soberanía del pueblo y de la forma republicana de gobierno". Esta norma no figuraba en el texto originario de 1853; se incorporó en la reforma de 1860, y tuvo como fuente directa la enmienda IX de la Constitución norteamericana. La doctrina ha señalado que la fórmula argentina es defectuosa porque parece referirse solo a los derechos políticos, no a los llamados derechos civiles. Sin embargo, hay acuerdo en interpretar el texto a la luz de su fuente y, consecuentemente, comprende a ambos tipos ${ }^{47}$. Esta es también la solución del art. 29 de la Convención Americana de Derechos Humanos que señala: "Ninguna disposición de la presente Convención puede ser interpretada en el sentido de

\footnotetext{
44 DABOVE (2000) p. 1024.

45 La corrupción y la emergencia han causado efectos desvastadores en el derecho de los jubilados; la "clase pasiva" argentina se ha visto privada, incluso, del acceso a la justicia, con medidas a todas luces inconstitucionales que impidieron ejecutar las deudas del Estado. La cuestión no es solo argentina y ha llegado hasta la Corte Interamericana de Derechos Humanos, que el 28/2/2003 decidió: "Los Estados Partes en la Convención Americana de Derechos Humanos no pueden variar el mecanismo de nivelación del monto de las pensiones, ocasionando su reducción, a menos que ello se instrumente por vía legal y existan razones de utilidad pública o interés social que lo sustenten, pues el otorgamiento de una pensión nivelada es un derecho adquirido cuya vulneración atenta contra la garantía de la propiedad -art. 21 Convención citadamáxime si existe una condena judicial firme e incumplida, dictada en contra del Estado por sus propios tribunales internos" (LL 2003-D-453, con nota de González Campaña, Germán, El final de la doctrina Chocobar. La reducción de jubilaciones por emergencia provisional frente a la Corte Interamericana. La Corte Suprema de la Nación argentina adecuó su jurisprudencia a la de la Corte Interamericana en sentencia del 17/5/2005 (Ver ed 214-237 y LL 2005-C-612, con nota de MorelLO, Augusto y GonZÁLEZ Campaña, G., Reflexiones sobre el abandono de la doctrina Chocobar).

46 ZURITA (2004) p. 120.

47 JIMÉNEZ (1992) p. 1053.
} 
excluir otros derechos y garantías que son inherentes al ser humano o que se derivan de la forma democrática representativa de gobierno".

\section{ANCIANOS Y ÁMBITOS DE LA SEGURIDAD SOCIAL DIVERSOS AL RÉGIMEN DE JUBILACIONES Y PENSIONES}

Probablemente, la seguridad social es el ámbito en el que la ancianidad apareció legislada por primera vez ${ }^{48}$; no obstante, aún hoy es un área que presenta problemas muy difíciles de resolver desde que aparece sensiblemente imbricada en todo cuanto concierne a las políticas económicas ${ }^{49}$.

Como no podía ser de otro modo, las diversas crisis económicas argentinas han llegado a los tribunales en numerosas ocasiones. Me referiré solo a la última crisis, la del año 2001, aún no superada. Como es habitual en los últimos años, los débiles reclaman justicia, aunque hacer justicia signifique que el tribunal, para poder resolver el caso particular, deba bordear pautas macroeconómicas que son responsabilidad de los otros poderes del Estado.

Tal lo sucedido, incluso, con planes o subsidios establecidos por los poderes políticos a favor de los ancianos que cumplen determinados recaudos legales. La revocación de esos subsidios suele motivar peticiones judiciales; la Administración responde que se trata de actividades discrecionales sobre las cuales el Poder Judicial no tiene injerencia; no obstante, la intervención jurisdiccional es posible si se prueba arbitrariedad, discriminación, carencia de legalidad, etc. En esta línea, se ha ordenado a la Obra Social de la Ciudad de Bs. As. continuar prestando la debida asistencia a su afiliada a través de la renovación del subsidio por geriatría que venía percibiendo, "toda vez que no basta con que la actora tenga familiares obligados en los términos de la resolución 113/2003, ya que es necesario que estos puedan afrontar los gastos que la atención demanda, pues en caso contrario, quedaría sin ayuda económica alguna" 50 .

Más aún, aunque excepcionalmente, la medida autosatisfactiva ha sido utilizada como medio procesal rápido para obligar al organismo estatal a otorgar una jubilación por invalidez "cuando el estado de salud del solicitante es de una gravedad tal (invalidez del 70\%) que, en principio, podría ser fatal”. En el caso, la persona tenía a su favor una sentencia que obligaba a la Caja a modificar el criterio denegatorio y seguir la jurisprudencia de la Corte Federal en la materia; en el procedimiento administrativo se había

48 Compulsar, a vía de ej., MARSIGLIA, Miguel A., Legislación asistencial a la vejez e invalidez en Legislación del trabajo t. XXVIII-B-1029; PitTAMiglio (1989).

${ }^{49}$ Compulsar, entre muchos, PoCIELlo (2002), pp. 89-132.

50 Contencioso-administrativo y Trib. Ciudad Autónoma de Bs. As., sala II, 1/4/2005, LL 2005-C-648. Para otorgar el subsidio, la reglamentación mencionada exige: (a) ser dependiente o semidependiente mayor de 70 años; (b) carecer de vivienda propia; (c) tener escasos recursos para afrontar el gasto; (d) carecer de familiares obligados. En el caso, una hija vivía en Canadá y la otra, que vivía en Argentina, no trabajaba y su esposo tenía una remuneración de alrededor de quinientos pesos. El tribunal también tuvo en cuenta que cuando el subsidio se revocó, solo se dijo que el caso no encuadraba en la resolución, sin indicar cuál era el requisito que no se cumplía, omisión que recién se salvó al contestar la demanda. 
vuelto a denegar la jubilación, por lo que el juez dispuso el otorgamiento a través de la medida autosatisfactiva reseñada ${ }^{51}$.

\section{ANCIANOS Y DERECHO DE LA SALUD}

La República Argentina asiste a lo que se ha dado en llamar el "amparo salutífero" ${ }^{2}$. Las resoluciones judiciales que protegen el derecho a la salud de los ancianos son muy numerosas. Me limito a reseñar una de ellas con el deliberado propósito de mostrar hasta dónde han llegado algunos jueces argentinos cuando enfrentan las urgencias de los ancianos.

Así, por ej., se acogió la medida cautelar y se obligó a la obra social de las Fuerzas Armadas del Estado a pagar el costo de internación en una clínica gerontológica privada de un anciano con carencias de salud mental ${ }^{53}$. En el caso, el juez de primera instancia había ordenado a la mutual cubrir el $60 \%$ del costo de la internación; valoró que los gastos mensuales de internación del paciente resultaban excesivamente altos y no podían cubrirse con su jubilación. La obra social de la Fuerza Aérea argentina demandada apeló. Se quejó de violación al derecho de defensa, desde que la cautelar había sido dictada en un expediente donde no había sido oída. El tribunal rechazó la alegación; afirmó que el derecho a la salud puede entrar en colisión con otro derecho fundamental cual es el de la defensa en juicio, y si bien este debe ser respetado a ultranza, en el caso no existía la violación denunciada pues en las medidas cautelares el juez debe solamente constatar el cumplimiento de los requisitos que la condicionan, y el derecho del afectado queda resguardado a través del pertinente recurso de apelación. En cuanto al fondo del asunto, la jurisdicción afirmó que "frente a una cuestión particularmente sensible que afecta a una persona en situación de vulnerabilidad, no le basta a la obra social invocar que no tiene obligación de brindar la prestación de que se trata. La Corte Federal ha entendido que, como pauta interpretativa, debe estarse al objeto social de las obras sociales, priorizando su compromiso social. Si bien se debe tener presente el carácter comercial de la entidad, ella se ordena a proteger los derechos fundamentales a la vida, salud e integridad de la persona, lo que importa asumir un compromiso social (C.S.N., 13/3/2001, J.A. 2001-III-390). La mutual sostiene que ella no brinda cobertura del tipo de prestación que se le exige ( $60 \%$ del costo de la internación); sobre la base de los tratados internacionales, el tribunal responde que el accionar del apelante acrecienta la estigmatización por afección mental y vulnera derechos elementales a la vida, a la dignidad, a la salud y a la integridad sicofísica del paciente".

\footnotetext{
51 Juz. Fed. Seg. Social $n^{\circ}$ 7, 17/3/2000, Doc. Jud. 2000-3-609. La carencia de publicación me ha impedido hacer el seguimiento de esta decisión de primera instancia. Desconozco el destino final (si fue o no revocada por los tribunales superiores).

52 Morello (2002) p. 1212.

53 Cám. Civil y Com. de Mar del Plata, Sala II, 5/8/2004, J.A. 2005-II-361, con nota de ToselLI, Juan, El reconocimiento de la dignidad de las personas con padecimientos mentales.
} 
Con el mismo criterio anterior y fundado en el derecho de los consumidores, se ha declarado abusiva la cláusula del contrato de medicina prepaga que faculta a la empresa a aumentar la cuota de modo unilateral, el día que el afiliado cumple 70 años ${ }^{54}$.

\section{ACCESO Y PERMANENCIA DEL ANCIANO EN EL MUNDO LABORAL}

Las restricciones al acceso y a la permanencia en los puestos de trabajo fundadas en una edad tope han dado lugar a un gran debate.

En cuanto al acceso, la Corte bonaerense ha resuelto que "la norma que establece como requisito para la inscripción en los listados oficiales de ingreso a la docencia el límite de cuarenta y cinco años de edad es discriminatoria y contradice el derecho a trabajar y a la igualdad ante la ley consagrado en la Constitución nacional, en la Constitución de la provincia de Bs. As. y en los tratados internacionales incorporados a dichas constituciones" 55 . A igual conclusión llegó el Tribunal de la Ciudad de Bs. As. respecto del Estatuto docente municipal para el ingreso a la carrera docente que establece como límite tope para el ingreso la edad de cuarenta años ${ }^{56}$.

Ambas decisiones han tenido en consideración que según la Corte Federal, "las leyes son susceptibles de cuestionamiento constitucional cuando resultan irrazonables, o sea, cuando los medios que arbitran no se adecuan a los fines cuya realización procuran, o cuando consagran una manifiesta iniquidad" 57 y el requisito de la edad tope presenta tales características de irrazonabilidad.

Con relación a la permanencia en la función, en la causa conocida como caso "Franco", la Corte de la Nación decidió que "el art 32 inc. 1 del dec. ley 9020/78, en cuanto dispone como causal de inhabilidad para ejercer funciones notariales la edad de 75 años, establece una presunción iuris et de iure de que quienes alcanzan dicha edad se encuentran incapacitados para ejercer funciones notariales, resultando arbitrario debido a su generalidad y a su falta de sustento racional, además de vulnerar el derecho de trabajar y la garantía de igualdad ante la ley consagrados en la $\mathrm{CN}$ y en los tratados internacionales de jerarquía constitucional ${ }^{58}$.

Quizás, en la solución incidió lo resuelto anteriormente por el tribunal en el caso "Fayt", que declaró la inconstitucionalidad de la reforma constitucional que limitó la

\footnotetext{
54 Cám. Nac. Com. Sala C, 8/3/2005, LL 2005-E-873, ED 213-43 y ElDial.com. 14/4/2005. Otros tribunales han llegado a la misma solución. Ver ROMERO (2005) p. 314.

55 S.C. Bs. As., 19/2/2002, Briceño c/Dirección General de Cultura y Educación, La Ley Bs. As., 20021392, y en JA 2003-II-427, con nota de SPACAROTEL, Gustavo y MARTínez PASS, Laura, El límite de edad para ejercer la docencia en la provincia y el plazo de caducidad en la acción de amparo bonaerense.

56 TS Ciudad de Bs. As., 29/11/2000, SAndeZ, Carlos c/Gobierno de la Ciudad de Bs. As., LL 2001-B580, con nota aprobatoria de Gauna (h) Juan O., Un amparo contra la discriminación por razones de edad 57 Fallos 308-418; 311-395.

58 CSN, 12/11/2002, LL 2003-B-286, Doc. Jud. 2003-4-666; JA 2003-II-464. Ver comentarios laudatorios de GÓMEZ (2003) p. 311; Rivera (2003) p. 261.
} 
permanencia de los jueces de la Corte hasta la edad de setenta y cinco años ${ }^{59}$, decisión que había sido precedida por sentencia del 22/6/1999, que había nulificado un artículo de la Constitución de la provincia de Santa Fe según el cual "cesa la inamovilidad de los magistrados a los sesenta y cinco años de edad si están en condiciones de obtener jubilación ordinaria" 60 .

La problemática de los jueces ancianos y la necesidad de su recambio es clásica en el Derecho Constitucional. Los autores ${ }^{61}$ recuerdan el proyecto del presidente norteamericano Roosevelt de modificar la estructura de la Suprema Corte, que sorprendió a sus propios partidarios y provocó la crítica de la prensa independiente. En efecto, para doblegar la intolerancia de la mayoría del tribunal, Roosevelt ideó una especie de "curatela" para los jueces que llegaran a los 70 años; al cumplir esa edad, cada juez se hallaría desempeñando su función conjuntamente con otro magistrado más joven que "vitalizaría" al tribunal, inyectando "sangre nueva". En el Mensaje de elevación del proyecto decía uno de los presidentes más amados por el pueblo norteamericano: "Solo en casos excepcionales los jueces, como los demás hombres, retienen hasta edad avanzada su pleno vigor mental y físico". "También el jurista es un hombre de carne y hueso y no un esquema". "El disminuido vigor mental o físico lleva a los hombres a evitar los exámenes complicados y las condiciones modificadas de la vida. Poco a poco los nuevos hechos aparecen borrosos a través de los antiguos lentes, apropiados para las necesidades de otra generación; hombres viejos ven la escena lo mismo que en el pasado, dejando de explorar o inquirir en el presente o en el futuro".

Quienes se pronunciaron a favor del proyecto dijeron que casi siempre, no obstante conservar su capacidad mental, los jueces que han sobrepasado los 70 años ven disminuir progresivamente su vigor intelectual. No obstante, se reconoce que si jueces como Holmes hubieran sido obligados a retirarse a los 70 años, la Constitución y las leyes de los EE.UU. habrían empobrecido en su trayectoria jurisprudencial.

59 CSN 19/8/1999, LL 2000-C-540, con nota de Mario Midón, Los límites del poder constituyente; a propósito del caso Fayt; JA 1999-IV-616, con nota de Carlos Colautti, Las reformas a la constitución y los límites de la revisión judicial, y ED 184-979 con nota de Alberto Bianchi, Los efectos del caso Fayt sobre la reforma constitucional de 1994. Se comparta o no la solución del caso, cabe advertir la errónea técnica constitucional; la limitación aparece en el art. 99 inc 4 de la CN, "oculta" entre las atribuciones del Poder Ejecutivo. El art. 99 inc 4 dispone que el PE "nombra los magistrados de la Corte Suprema con acuerdo del Senado por dos tercios de sus miembros presentes, en sesión pública, convocada al efecto. Nombra los demás jueces de los tribunales federales inferiores en base a una propuesta vinculante en terna del Consejo de la Magistratura, con acuerdo del Senado, en sesión pública, en la que se tendrá en cuenta la idoneidad de los candidatos. Y concluye en el último párrafo: "Un nuevo nombramiento, precedido de igual acuerdo, será necesario para mantener en el cargo a cualquiera de esos magistrados, una vez que cumplan la edad de setenta y cinco años. Todos los nombramientos de magistrados cuya edad sea la indicada o mayor se harán por cinco años, y podrán ser repetidos indefinidamente, por el mismo trámite”.

60 CSN 22/6/1999, Iribarren, Casiano R cl Provincia de Santa Fe, Acción declarativa, ED 186-863. La provincia se defendió diciendo que no había cese automático de la función sino que el magistrado podía seguir en el cargo, pero sin estabilidad. La mayoría sostuvo que esa norma, al dejar al magistrado en situación precaria, violaba la independencia de los jueces. Belluscio entendió que la Corte no podía analizar la conveniencia o inconveniencia de las normas y que la norma provincial no merece reproche por una supuesta colisión con las normas nacionales.

${ }^{61}$ Ver, entre otros, JUsTO p. 109. 
Por mi parte, coincido con quienes afirman que el propósito de situar al juez en el mundo en que vive no puede ser objetado, y con tal finalidad, la limitación de la edad tiene un fundamento de valor.

\section{ANCIANIDAD Y CAPACIDAD CIVIL ${ }^{62}$}

Normalmente, la edad mínima es un presupuesto de capacidad de ejercicio. En cambio, la edad máxima no lo es. No obstante, la ancianidad no es un factor neutro para el derecho privado.

La cuestión ha tenido acceso a los tribunales en temáticas muy variadas; he elegido las referidas a la inhabilitación y a la nulidad del testamento, por ser las más frecuentes.

\subsection{Autotutela, VOluntades anticipadas, poderes de personas INCAPACITADAS}

La posibilidad de designar uno mismo a su curador en previsión de una futura incapacidad, no ha sido legalmente regulada en Argentina, omisión legislativa que preocupa a la doctrina ${ }^{63}$. Tampoco han merecido la atención del legislador ni las llamadas voluntades anticipadas ${ }^{64}$, ni los poderes de personas incapacitadas. No obstante, la jurisprudencia comienza a reaccionar positivamente frente a estas figuras ${ }^{65}$.

\subsection{LOS ANCIANOS Y LA INHABILITACIÓN JUDICIAL}

Jurisprudencia reiterada de la República Argentina distingue entre la simple ancianidad y la senilidad calificada que ocasiona la incapacitación o la inhabilitación, según el grado que presente; en otros términos, "senectud o ancianidad normal no equivale a senilidad patológica. Si bien no siempre hay nitidez absoluta entre un supuesto y otro, porque puede darse una evolución del cuadro normal de ancianidad que coloque al sujeto en un estado límite cuya dimensión sea arduo fijar con precisión, es incontrovertible que la vejez, por sí, no es sinónimo de enfermedad, aun cuando implique disminución de facultades de la persona"66.

Con igual criterio se decide que "la ancianidad, como proceso fisiológico normal no excluye la salud. En virtud de ello, no corresponde entender que no gozan de ella personas en quienes la ciencia médica no registra modos de ser anormales en relación a su edad, máxime si, como en el caso, tampoco se ha demostrado el elemento jurídico

\footnotetext{
62 Para la cuestión en España ver Zurita (2004) pp. 55 y ss; De Couto (1999); GanZanmüller y ESCUDERO (2005); ROVIRA (2005); SERRANO (2003).

${ }^{63}$ La doctrina, en cambio, viene preocupándose del tema desde hace más de una década. Para el tema ver, entre otros, Taiana y Llorens (1996); Wilde (2005a) p. 73 y en Rev. del Notariado n 873, p. 127. La cuestión de las voluntades anticipadas ha sido objeto de importantes estudios desde la Bioética.

${ }^{64}$ Compulsar, entre muchos, MERINO y Hernández (2002-2003) p. 325.

65 Comentarios a la decisión del Juez Crim. y Correc. de Transición n 1, Mar del Platal del 25/7/2005, de KrAUT (2005), p. 362, y de SAMBrizZI (2005) p. 451.

${ }^{66}$ Cám. Nac. Civ. sala D, 22/6/1982, LL 1983-A-312, con nota de MÉNDEZ (1975) p. 1229.
} 
determinante de la restricción a la capacidad, esto es, la presumibilidad de daño en mérito a circunstancias distintas de la biológicas. El temor de que el anciano no haga buenos negocios, como cualquier persona, no tiene su remedio en la inhabilitación si se acredita un estado patológico" 67 , aunque en algún caso puede llegar a configurarse una estafa ${ }^{68 "}$.

\subsection{ANCIANOS Y NULIDADES TESTAMENTARIAS}

Risolía decía que "la vejez suele ser avariciosa, maneja la disposición de su patrimonio como quien distribuye premios y castigos y cae en las celadas que le tiende el amor simulado o el espectro de la relegación y el abandono. Hay vejeces que mueren asidas al derecho de propiedad, pensando y repensando los capítulos de la evolución sucesoria, del seguro o del contrato de renta vitalicia”. Por esta, y por otras muchas razones, son frecuentes los casos en los que los jueces deben transar el conflicto que genera la tensión entre la voluntad del testador, que se pretende preservar, y la existencia de indicios relativos a la captación de la voluntad del anciano. En la mayoría de los supuestos en los que existen discrepancias entre los integrantes del tribunal, las dificultades son de orden probatorio desde que hay cierto acuerdo en que "para realizar un acto de última voluntad no se requiere mayor discernimiento que el necesario para realizar actos entre vivos; por ende, no todos los ancianos que están afectados por enfermedades psicofísicas (arterosclerosis, diabetes, afecciones cardíacas, etc.) deben ser considerados como carentes de entendimiento para comprender la naturaleza de los actos que reali$\operatorname{zan}^{69}$.

A esta tensión no fue ajeno, incluso, el testamento de uno de los más grandes de la literatura argentina, Jorge Luis Borges, que dio lugar a un largo proceso judicial en el que se discutía si la ancianidad del prestigioso literato era o no demencia senil y, consecuentemente, si era o no nulo el testamento que tenía por beneficiaria a María Kodama ${ }^{70}$.

\footnotetext{
${ }^{67}$ Cám. Nac. Civ. sala A, 1/6/2004, ED 209-206; en el caso, la anciana vivía con una hermana, presuntamente discapacitada, desarrollando una vida en un clima adecuado; contaba, además, con asistencia doméstica y no se había acreditado dilapidación de bienes; por lo tanto, se rechazó el pedido de inhabilitación y el de demencia. El mismo tribunal se había pronunciado, en igual forma, el 21/10/1993, ED 159-424; en este precedente se trataba de una anciana de 82 años que, luego de un accidente, había quedado con una afasia, que le afectaba la expresión y articulación del lenguaje pero presentaba un alto nivel intelectual y la comprensión se hallaba intacta.

${ }^{68}$ ESCRIVÁ, José M., Aproximación desde el derecho penal: la estafa, en Villagrasa (2002) p. 89. Para los problemas penales de la ancianidad ver CARRIERI, F., GReCO, O., y CATANESI, R. (1992); esta obra afronta el problema del anciano víctima y el anciano autor.

${ }^{69}$ Cám. Nac. Civ. Sala F, 20/8/1998, JA 2000-I-595. En el caso, se rechazó la demanda por nulidad de testamento interpuesta por el hermano de la causante contra la heredera instituida, una persona del vecindario que la cuidó en los últimos años. La sentencia tiene voto disidente de la Dra. Highton, quien consideró, con sólidos fundamentos, que se había captado la voluntad de la testadora.

70 Cám. Nac. Civ. sala G 5/6/1995, Uveda de Robledo c/Kodama, María s/Nulidad de testamento, ED 163-521. En ese largo proceso, iniciado por quien fuera el ama de llaves de Borges durante muchos años, fueron testigos figuras relevantes de la vida intelectual argentina; el dictamen del fiscal transcribe gran parte de estos testimonios. Borges hizo tres testamentos, uno en 1970, otro en 1979, y el último en 1986; la impugnación no prosperó y el acto de última voluntad fue declarado válido.
} 


\subsection{ANCIANOS Y AUSENCIA CON PRESUNCIÓN DE FALLECIMIENTO}

La Ley 14.394 regula el régimen ordinario de la ausencia con presunción de fallecimiento. La ancianidad juega un solo rol. Según el art. 30, "Transcurridos cinco años desde el día presuntivo del fallecimiento $u$ ochenta desde el nacimiento de la persona, quedará sin efecto la predotación prescrita pudiendo desde ese momento disponerse libremente de los bienes".

\section{ANCIANIDAD Y RELACIONES DE FAMILIA}

\subsection{LA REALIDAD SOCIAL}

El anciano y su familia son sujetos frecuentes de decisiones judiciales.

Las causas del conflicto son muy variadas. Recientemente, se ha puesto de resalto que el incremento de lo que hoy se llama "adultescencia", es decir, "el tardío desapego de los hijos del hogar familiar, que se prolonga con casi todas las exigencias de la edad de la infancia en la edad adulta, como la asistencia alimentaria, habitacional, recreativa y educacional, impide en gran medida que quienes ya deberían estar en condiciones de asistir a sus propios padres en la red de solidaridad familiar, todavía deban ocupar su tiempo y recursos en atender a estos hijos adultescentes. A esto se ha sumado la incorporación masiva de la mujer al mercado laboral lo que ha determinado que la costumbre muy arraigada que la hija se hace cargo de los padres ancianos haya prácticamente desaparecido"71.

Por otro lado, se ha puntualizado que vejez y familia convergen en el tema de la abuelidad. Este es uno de los pocos roles en la vida que no se elige y se manifiesta en sentimientos, pensamientos y acciones que reciben influencias muy diversas, entre otras, la experiencia personal del sujeto como nieto, cómo fueron sus padres como abuelos, las actitudes sociales dominantes hacia los viejos y los abuelos, etc. Se señala que en el mundo actual, caracterizado por una gran tensión respecto de la situación económica, hay dos roles significativos para los abuelos: Por un lado, en las sociedades industriales, el abuelo vuelve a asumir el papel de "agente sustituto de socialización", aquel que Margare Mead encontró en sociedades más tradicionales o primitivas. Por el otro, los abuelos son agentes secundarios de apoyo económico en los casos en que se produce la ruptura o un desenlace negativo en la pareja del hijo o la hija, y como maneja la crisis económica, se convierte en una suerte de árbitro de los conflictos familiares. "Es un rol de gran desgaste, ya que generalmente no se tienen los recursos suficientes para reparar los desajustes psicosociales en la familia. Los abuelos no son agentes de salud familiar; no están adiestrados para ser agentes que favorezcan la salud mental del cuadro familiar $y$, por lo tanto, tienen que cargar con la proyección de enojos y de culpas de los otros miembros de la familia que esperan el cumplimiento de esa función omnipotente"72.

\footnotetext{
${ }^{71}$ Morcillo (2004) p. 844.

72 Tomasello (2002) p. 930.
} 
Aunque no asuman este rol, al parecer hay dos clases de ancianos en la vivienda familiar: los dependientes y los que se encargan del cuidado de los nietos o bisnietos. Ambas son generadoras de conflictos. En cuanto a la segunda, es verdad que en la edad anciana "los papeles familiares no están solo definidos para recibir ayuda, sino también para ofrecerla; que los abuelos hacen tomar conciencia de las propias raíces, empalman con el ayer, reafirman en una continuidad de vida, aportan el sentido común y la sensatez propios de la mayor edad, se hayan presentes en la vida de los nietos con un marcado signo de amor-refugio, de saber y querer escuchar siempre, de disponer de tiempo para compartir"73; pero también es cierto que, en algunas ocasiones, la sustitución de los roles es fuente de diversas tensiones en el ámbito familiar.

\subsection{ANCIANIDAD Y CAPACIDAD PARA EL "ACTO JURÍDICO FAMILIAR"}

La ancianidad no es, en sí misma, causal de incapacidad para celebrar ninguno de los llamados "actos jurídicos familiares".

Una persona puede contraer matrimonio sin límite de edad máxima.

Teóricamente, también puede adoptar sin ese tipo de restricciones pues la ley argentina no establece ni edad tope, ni diferencia de edad máxima; esto significa que una persona muy anciana podría adoptar a un niño recién nacido. No obstante, el art. 321, inc. d) del Cód. Civil dispone que "en el juicio de adopción el juez valorará si esta es conveniente para el menor teniendo en cuenta los medios de vida, las cualidades del adoptante, y la diferencia de edad entre adoptante y adoptado". También debe recordarse que la ley prohíbe a los abuelos adoptar a sus nietos (art. 315 inc b del CC argentino).

\subsection{LA ESCASA NORMATIVA CIVIL}

El código civil argentino contiene pocas normas relativas a los deberes y derechos entre los ancianos y su parentela; entre ellas se destaca el art. 266 que establece: "Los hijos deben respeto y obediencia a sus padres. Aunque estén emancipados, están obligados a cuidarlos en la ancianidad y en estado de demencia o enfermedad, y a proveer a sus necesidades en todas las circunstancias de la vida en que le sean necesarios sus auxilios".

Pueden mencionarse, además, normas sobre prestación alimentaria, derecho de visitas a los nietos, contra la violencia familiar (ley 24417, que prevé protección al anciano frente a hechos puntuales de mal trato $)^{74}$.

\subsection{ANCIANOS Y DEBER DE ASISTENCIA}

Bien se ha dicho que "la solidaridad es un deber moral que, al ser reconocido por la ley, asume la naturaleza de obligación civil. La sociedad y la familia son conjuntos solidarios que obedecen a la ley de interdependencia universal porque nada es el producto exclusivo de las fuerzas y desvelos de una sola persona ${ }^{75}$.

\footnotetext{
73 Gonem Machello de Gandolfo (1999) p. 2.

74 BarrionueVo DE Romero (2005) p. 1070.

75 FANZOLATO (1996) p. 11. El autor reproduce la ponencia presentada ante el IX Congreso Mundial de Derecho de Familia, Panamá, 1996; compulsar Daino, Miranda (1997) p. 195.
} 
Por eso, el art. 367 establece la obligación alimentaria a favor de los ascendientes sin limitación de grados por consanguinidad, y en el primer grado de afinidad. Por su parte, la ley 14394 prevé el delito de incumplimiento de los deberes de asistencia familiar respecto de los hijos que se sustrajeran a prestar los alimentos indispensables para la subsistencia de sus padres impedidos, aun sin mediar sentencia judicial, imponiendo multas y penas de prisión.

\subsection{ABUELOS Y DERECHOS DE VISITAS}

Los abuelos (ancianos o no) pueden prevalerse del art. 376 bis que establece la obligación del guardador de permitirles las visitas ${ }^{76}$. En efecto, en el derecho de familia argentina los abuelos están obligados a pasar alimentos ${ }^{77} \mathrm{y}$, correlativamente, también tienen derecho de visitas, si estas son negadas por los padres ${ }^{78}$.

\subsection{ANCIANOS Y VIOLENCIA FAMILIAR}

El tema del maltrato hacia los ancianos es muy complejo; intervienen muchos factores (biológicos, psicológicos, de estructura sociocultural y espirituales); un microsistema familiar y personal y un macrosistema general provocan situaciones, muchas veces avaladas con el silencio ${ }^{79}$. En efecto, los "abusos" o malos tratos de diversa índole han permanecido ocultos durante mucho tiempo; recién en los últimos años han accedido a los tribunales y a los medios de comunicación.

\footnotetext{
${ }^{76}$ Morcillo (2004) p. 844.

$77 \mathrm{El}$ art. 367 dispone: Los parientes por consanguinidad se deben alimentos en el orden siguiente: 1. Los ascendientes y descendientes. Entre ellos estarán obligados preferentemente los más próximos en grado y a igualdad de grados, los que estén en mejores condiciones para proporcionarlos.

${ }^{78} \mathrm{El}$ art 376 bis CC dispone: Los padres, tutores, curadores de los menores e incapaces o quienes tengan a su cuidado personas mayores de edad enfermas o imposibilitadas deberán permitir las visitas de los parientes que conforme a las disposiciones del presente capítulo se daban recíprocamente alimentos. Si se dedujere oposición fundada en posibles perjuicios a la salud moral o física de los interesados, el juez resolverá en trámite sumario lo que corresponda, estableciendo en su caso el régimen de visitas más conveniente de acuerdo a las circunstancias del caso". Para este tema ver CHECHILE (2005) p. 100. En la Argentina, nadie ha osado a sostener que se trata de una norma inconstitucional. En cambio, que en la causa Jennifer Troxel v/Tommie Granville del 5/6/2000, la Corte Federal norteamericana declaró la inconstitucionalidad, para el caso concreto, por su excesiva amplitud, de una ley similar del Estado de Washington (Rev. Derecho de Familia n 23, p. 211; compulsar Wagmaister, Adriana, Tropel v/ Graville. La Suprema Corte de los EE.UU. define la extensión del derecho de visitas de los abuelos en función de la autoridad de los padres, Derecho de Familia ${ }^{\circ} 29$, p. 226). El voto mayoritario fue redactado por la jueza Sandra O'Connor y se fundó en la libertad de los padres como uno de los derechos fundamentales desde los orígenes de la fundación de los EE.UU. De cualquier modo, la mayoría no dijo que la ley fuese siempre inconstitucional, sino que lo era en este caso, en que nadie había negado la competencia de la madre para decidir cuál era el mejor interés de sus hijas. El padre de las niñas se había suicidado; la madre había contraído un nuevo matrimonio y las visitas eran solicitadas por los abuelos paternos. En el artículo de Wagmaister pueden leerse otros casos de la jurisprudencia norteamericana. La autora señala que la decisión recaída en Tropel v/ Granville es considerada como una de las más importantes de los últimos años en materia de derecho de familia. En España, al igual que en la Argentina, el derecho de visitas de los abuelos nació con una ley posterior a la sanción del código civil que recogió creaciones pretorianas; en el caso, la ley 42/2003 del 21/11/2003. Compulsar García (2004); ZURITA (2004) p. 19; COLÁs (2005).
}

79 Rivero (2002) p. 291. 
Utilizo la palabra violencia en sentido amplio, como lo hacen casi todas las leyes de violencia familiar, comprensivo de la violencia física, psíquica, incluso económica, ejercida tanto por actos positivos como negativos manifestados a través de la negligencia, el abandono, la falta permanente de preocupación, la desatención continua de las inquietudes, opiniones, etc. ${ }^{80}$.

Para algunos autores, la agresión ejercida contra el anciano constituye un tipo particular de violencia, "porque opera bajo el móvil del desprecio, bajo la pretensión del no precio, o no valor, que el agresor adjudica al anciano. De allí que no sea casual encontrar relaciones estrechas entre la violencia y el sistema económico" 81 .

Normalmente, la violencia al viejo opera a través de la manipulación, mecanismo psicológico de control. "Generalmente, al viejo no se le pega como a los menores de edad, pero se los maltrata a través del lenguaje y de lo que podría llamarse la teoría de los hechos consumados (por ej., se lo interna sin su consentimiento, se vende un inmueble bajo la promesa de una renta vitalicia, etc.)" 82 .

Un informe publicado por la Organización Panamericana de la Salud para la Organización Mundial de la Salud del año 2002 dice que el maltrato de los ancianos a manos de sus parientes u otros cuidadores es un problema social grave, que va en aumento. De cualquier modo, hay muy poca información sobre la magnitud del maltrato de ancianos ${ }^{83}$.

\section{LOS ANCIANOS Y LOS GERIÁTRICOS DESDE LA ÓPTICA CONTRACTUAL}

El aumento del número de ancianos alojados en geriátricos es muestra, entre otros factores, del espacio vacío dejado por la familia ${ }^{84}$.

"Los geriátricos constituyen fenómenos jurídicos complejos en su definición y en su funcionamiento. Se trata de un instituto jurídico polisémico; en su configuración intervienen normas de derecho público y reglas de derecho privado. Lamentablemente, la historia argentina muestra una estrecha dependencia entre los geriátricos y los vaivenes de las políticas sociales en boga" 85 .

El fenómeno también se enmarca dentro de uno de los signos visibles de la economía contemporánea, caracterizada por una fuerte expansión del sector de los servicios prestados a consumidores, dentro de los cuales es posible ubicar a la prestación de servicios geriátricos. Desde esta perspectiva, el anciano actúa como un consumidor o

\footnotetext{
80 CADOCHE (2002) p. 94 y (2002) p. 31.

${ }^{81}$ Dabove, María I., Violencia y ancianidad, en Doc. Jud. 1999-2-1165.

82 Dabove, María I., Violencia y ancianidad, en Doc. Jud. 1999-2-1166.

${ }^{83}$ MorCillo (2004) p. 844.

${ }^{84}$ De cualquier modo, según datos de la Organización Panamericana de la salud, por muy diversas causas, en América Latina, la mayoría de las personas de edad sigue viviendo en el ámbito familiar (Ver datos en WiLDE (2005) p. 149).

85 Dabove, María I. (2005) p. 51. De la misma autora (2000) p. 205.
} 
usuario en el cual la relación económica aparece teñida por un fuerte interés público que se exterioriza a través del poder de policía estatal ${ }^{86}$.

El contrato celebrado es atípico, bilateral, oneroso, de tracto sucesivo, de cambio. Desde esta perspectiva se ha resuelto que "la prestación de servicios de geriatría importa una relación contractual atípica que involucra un conjunto de servicios, que trascienden al simple suministro de alojamiento y alimentación, incluyendo también el cuidado, la vigilancia y la prestación médica convenida. Por ello, no puede asimilarse al simple hospedaje. Por otro lado, dado que la actividad del instituto geriátrico está organizada como empresa, se trata de una relación de tipo comercial ${ }^{87}$.

\section{ANCIANOS Y DERECHO DE LA EMERGENCIA}

\subsection{LA EMERGENCIA ECONÓMICA ARGENTINA}

Las continuas crisis de la economía argentina han llevado a la creación de un verdadero "derecho de la emergencia". El llamado "corralito financiero" es quizás el ejemplo más paradigmático, aunque no el único. Los jueces argentinos han intentado acompañar los remedios económicos instrumentados por los otros poderes del Estado cuando esas vías, por duras que sean, no implican la destrucción del derecho individual constitucionalmente amparado sino solo su restricción a través de la postergación en el tiempo. Cuando el titular del derecho es un anciano, ese aplazamiento puede llegar a ser eliminación lisa y llana; mostraré algunas decisiones judiciales que, a través de esta distinción, han permitido la conservación plena de su derecho.

\subsection{El Llamado "CORRALITO” FINANCIERO}

Son numerosos ${ }^{88}$ los casos que deciden que "Se encuentran configurados los requisitos exigidos para la procedencia de la acción de amparo, y el derecho lesionado de la apelante (derecho de propiedad) debe restituirse de modo inmediato, si se trata de la indisponibilidad de ahorros de una persona mayor de 75 años" 89 ; en este, como en tantos otros similares, la amparista sostuvo que los depósitos encerrados en el llamado "corralito" financiero, eran los ahorros de toda su vida y estaban destinados a solventar necesidades personales y familiares.

${ }^{86}$ Frustagli y Hernández (2005), p. 24.

87 Cám. Nac. de Comercio sala B 31/10/1997, Doc. Jud. 1998-2-565. En el caso, la demandada estaba organizada bajo forma de Soc. de Responsabilidad Limitada. El tribunal dijo que no era aplicable el plazo de prescripción del código civil para el servicio de hotelería y, además, que era competente la justicia comercial en una acción deducida contra el anciano por cobro de facturas impagas.

88 Cám. Fed. Córdoba, sala A, 24/5/2002, La Ley Córdoba 2002-737 (en el caso, la amparista tenía 80 años. El tribunal hace referencia a disposiciones de tipo administrativa que liberaron del corralito los depósitos de personas mayores de 80 años).

${ }^{89}$ Cám. Nac. Cont. Adm. Federal, sala III, 20/8/2003, ED 205-451. 


\subsection{CONSOLIDACIÓN DE LA DEUDA PÚBLICA}

La solución dada al anciano "víctima" del corralito reconoce importantes precedentes en los casos de consolidación de deudas del Estado. El efecto, el 29/4/1993, el conocido caso Iachemet, María ${ }^{90}$, la Corte Federal dijo que "debe declararse la inconstitucionalidad de la Ley 23.928 si su aplicación llevara no a una modificación del modo de cumplimiento de la sentencia pasada en autoridad de cosa juzgada, sino al desconocimiento sustancial de ésta, al no ser posible, sin forzar la letra ni el espíritu de la ley efectuar una interpretación que la haga compatible con la garantía del art. 17 de la CN".

Con igual criterio se ha resuelto que "la avanzada edad del peticionante (en el caso, setenta y nueve años) torna procedente la desconsolidación del crédito que tiene contra la provincia por reajustes de haberes jubilatorios" ${ }^{\prime 1}$, o por daños y perjuicios ${ }^{92}$ (en el caso ochenta y cinco años).

Para llegar a esta conclusión, los jueces recuerdan que según lo tiene dicho la Corte Federal desde antiguo "los jueces no pueden desentenderse de las consecuencias efectivas de sus decisiones, pues ellas constituyen un índice seguro del acierto de la hermenéutica. El régimen de consolidación es, en sí mismo constitucional; frente al grave padecimiento que a todos nos alcanza no resulta un despropósito diferir los pagos a cargo del Estado indigente, pues la integridad del crédito no está en juego desde que solo se postula el diferimiento de su pago y cobro para preservar el interés general sobre el particular. Cuestión muy distinta es la que hace a las calidades personales del actor, esto es, una avanzada edad".

\section{ANCIANOS Y DERECHO CONCURSAL}

Con el mismo criterio anterior, y considerando que la situación concursal es una especie de emergencia privada, se ha resuelto que "debe adelantarse el pago de un crédito concursal por indemnización de daños y perjuicios derivados de un accidente de tránsito pues someter el crédito de quien cuenta con 77 años de edad a la espera del acuerdo homologado importaría afectar el principio del derecho de propiedad amparado por el art. 17 de a Carta magna, ya que al finalizar la espera, la acreedora tendría 96 años, y por la expectativa de vida promedio traería como consecuencia el incumplimiento del acuerdo homologado". En el caso, la anciana había sufrido un accidente que le dejó una

\footnotetext{
${ }^{90}$ LL 1993-D-117. Para un análisis constitucional ver comentarios de Dante Cracogna y de Renato RabbiBaldi Cabanillas, en Rabbi-Baldi (1998), p. 229 y ss; también en HERrEndorf (1998), p. 267. En el caso Iachemet la mujer tenía 91 años y el plazo previsto para la restitución del dinero era 16 años. En cambio, en el caso Fernández Encarnación, resuelto el 4/5/1993, por razones formales vinculadas al consentimiento de anteriores decisiones, la Corte federal rechazó el amparo de una jubilada enferma, afectada de cáncer en estado terminal, acreedora de una deuda provisional de 15.000 , reconocida por el Estado, cantidad que requirió con urgencia para un tratamiento oncológico y una intervención quirúrgica de la que dependía su vida (Ver HERrENDORF (1998), p. 271).

91 Tribunal Contencioso-administrativo de Jujuy 17/11/2000, La Ley Noroeste 2001-38.

92 ST Jujuy, 3/8/1999, La Ley Noroeste, 2000-1209.
} 
incapacidad del $40 \%$ siendo transportada en un ómnibus cuyo propietario solicitó su concurso preventivo ${ }^{93}$.

\section{ANCIANOS Y DERECHO DE DAÑOS}

La ancianidad también aparece con frecuencia en el ámbito de la responsabilidad civil a la hora de cuantificar los daños ${ }^{94}$, valorar la culpa de la víctima ${ }^{95}$, determinar el deber de responder de los establecimientos donde los ancianos se encuentran alojados, etc.

Señalaré algunas reglas generales.

\subsection{DAÑO MATERIAL Y MORAL DEL ANCIANO VÍCTIMA}

Se ha resuelto que es improcedente la indemnización de la incapacidad sobreviviente reclamada por la víctima de un ilícito (en el caso, fue mordida por un perro) si se trata de un hombre jubilado que carece de actividad laboral adicional y posee una herida que se encuentra cubierta por la ropa la mayor parte del tiempo. En cambio, se indemnizó con 2.000 pesos argentinos el daño moral ${ }^{96}$.

Más aún, la mayor edad de la víctima puede ser un agravamiento para la procedencia de la elevación de la indemnización en concepto de daño moral ya que "a ciertas edades se sufre con mayor intensidad y hay menos capacidad de relación para sobrellevar dolores y disminuciones físicas". En el caso, la actora tenía 69 años, era soltera y jubilada y había sido atropellada cuando cruzaba la calle sobre la senda peatonal; se rechazó la indemnización por lucro cesante, porque la actora no acreditó las utilidades dejadas de percibir, pero se aumentó el daño moral ${ }^{97}$.

\subsection{DAÑO MATERIAL Y MORAL DE LOS DAMNIFICADOS INDIRECTOS}

La muerte de un anciano generalmente no produce daño material, desde que, normalmente, el damnificado no recibe ayuda de alguien que ya no produce. Sin embargo, en muchas ocasiones puede producir un grave daño moral. De cualquier modo, bien se ha señalado que "un derecho realista no puede desentenderse de las cuestiones de la vida; por eso, la muerte de quien en vida era un estorbo para los actores no puede volverse una fuente de enriquecimiento para los parientes ingratos ${ }^{98}$.

93 Sentencia de primera instancia del juez Carlos Ribera del 12/12/2003, González c/Microómnibus Gral. San Martín, LL 2004-F-790, con nota de TRUFFAT. La sentencia fue confirmada por la sala I de la Cámara $1^{\circ}$ de Apelaciones de San Isidro el 18/5/2004 (Ver LLBA 2004-818, con nota de Darío Graziabile, ¿Inconstitucionalidad del acuerdo preventivo homologado?, y en LL 2004-E-739, con nota aprobatoria de Mosset Iturraspe, Jorge, Otra muestra del derecho privado constitucional. La constitución avanza sobre los privilegios concursales.

${ }^{94}$ El tema ha sido desarrollado en Italia. Ver NeRI (1990), p. 415 y en STANZIONE (1991), p. 157.

95 El tema también ha preocupado en Italia; ver SICA, Salvatore, Anziani e responsabilità civile: a proposito del concorso di colpa del danneggiato, en Stanzione, Pasquale (1991), p. 127.

${ }^{96}$ CC y Comercial $1^{\circ}$ Nominación, Santiago del Estero, 16/4/2002, La Ley Noroeste 2002-1246.

97 Cám. Nac. Civ. Sala C, 22/12/1992, Doc. Jud. 1993-2-74.

98 Mosset (1995), p. 688. 
En cuanto a la forma de pago, se ha dicho que "el mecanismo de reparación en forma de renta periódica de la ley de riesgos del trabajo aparece consagrada a efectos de brindar, en caso de una familia obrera, con hijos menores o viudas jóvenes, una permanencia de ingresos perdurables durante un tiempo útil, tornándose inadecuado en el supuesto de una viuda de más de ochenta años y precaria salud (padece afecciones cardíacas, artereoesclerosis cerebral y trastornos en la marcha), en tanto la percepción en renta no le es útil para conjurar su situación de necesidad, por lo que cabe condenar a la aseguradora a pagar el total de la indemnización en una suma única"99.

\subsection{ANCIANIDAD Y CULPA O HECHO DE LA VÍCTIMA}

En algunas decisiones, la ancianidad ha jugado como factor de rompimiento del nexo causal. En este sentido se ha decidido que "No corresponde responsabilizar a la empresa propietaria de un edificio en cuyo interior la actora cayó por una escalera si esta estaba en condiciones reglamentarias y la actitud y características personales de la propia autora del daño, en el caso, de avanzada edad (70 años), con problemas cardíacos (tiene un marcapaso) y serias dificultades de visión (lleva permanentemente lentes bifocales), reúnen la condición de hechos de la propia víctima, con virtualidad para demostrar y rarificar la ausencia de culpa del establecimiento demandado ${ }^{100}$.

\subsection{RESPONSABILIDAD CIVIL DE LOS ESTABLECIMIENTOS GERIÁTRICOS}

La jurisprudencia argentina entiende que estos establecimientos asumen, respecto del anciano, un deber de seguridad. En esta línea se ha decidido que "debe responder el establecimiento geriátrico por los daños y perjuicios derivados del deficiente cuidado otorgado a una persona a su cuidado (en el caso, incorrecta aplicación de una inyección que afectó el nervio ciático a un anciano) pues si bien no se determinó quién efectivamente ocasionó el daño, se comprobó que el hecho ocurrió en el ámbito de la demandada ${ }^{101}$.

\section{ANCIANOS Y SISTEMAS CARCELARIOS}

El sistema carcelario argentino, como el de otras partes del mundo, está totalmente colapsado. En la mayoría de los casos, la situación de los internos está en contradicción palmaria con los derechos humanos más elementales.

Las normas y la jurisprudencia han intentado atenuar estos efectos nocivos cuando el delincuente es una persona anciana. Como vía alternativa de solución, muchas leyes regulan la detención domiciliaria.

\footnotetext{
${ }^{99}$ Cám. Nac. Trab. Sala 2, 10/8/1999, JA 1999-IV-24.

100 Cám. Nac. Civ. sala K, 22/5/2000, Doc. Jud. 2001-2-413. El juez de primera instancia había atribuido a cargo de la propietaria del edificio el $50 \%$ de los daños.

101 Cám. Nac. Civ. sala D, 3/10/1995, voto del Dr. Bueres, LL 1996-E-1, con comentario aprobatorio de VÁZQUez FERrEYRA, Roberto, Interesantes aportes en un fallo sobre responsabilidad civil de establecimientos asistenciales.
} 
Con criterio amplio, constitucionalmente justificable a la luz del principio de igualdad, se ha decidido que "es procedente el arresto domiciliario del imputado mayor de setenta años de edad que cumple prisión preventiva toda vez que el art. 33 de la ley de ejecución de la pena $24.660^{102}$ debe aplicase a quien goza de una mejor situación procesal que la que presenta todo condenado, pues no se quebró la presunción de inocencia; viola el principio de igualdad ante la ley y el de razonabilidad la denegatoria de cumplimiento de prisión preventiva bajo al modalidad de arresto domicilio de una persona mayor de setenta años, pues si la ley lo autoriza cuando está descartada la presunción de inocencia, con mayor razón es aplicable cuando subsiste la presunción" ${ }^{103}$, siendo irrelevantes la gravedad del delito imputado, el rol que desempeñó en la organización investigada, y la carencia de domicilio fijo en el país (en el caso, la hija asumió el compromiso del cuidado del imputado y ofreció un domicilio en la ciudad de Bs. As). El tribunal sostuvo que la prohibición de la analogía rige en el derecho penal pero no en el derecho procesal penal, si es a favor del imputado ${ }^{104}$.

En el mismo sentido, se ha declarado procedente "que el imputado (no condenado aún) cumpla en su domicilio la prisión preventiva a la cual se halla sujeto, dado su avanzada edad (78 años) y su restringida capacidad para moverse en forma autónoma en razón de la dolencia que padece (debe llevar en forma permanente un cuello ortopédico y le provoca mareos en la rotación cervical)" ${ }^{105}$.

\section{CONCLUSIONES}

No he intentado hacer una imagen idealizada de la ancianidad sino subrayar que cada uno en su ámbito, y los jueces en el suyo, no deben ahorrar esfuerzos para tratar de conservar a los ancianos en el seno de la sociedad, encontrándoles el lugar que por su dignidad y por sus aptitudes deben ocupar para bien de la comunidad. Una ética y un derecho de la ancianidad exigen valorar al anciano por el hecho de ser hombre y por todo aquello de positivo que puede aportar al mundo posmoderno ${ }^{106}$.

Fecha de recepción: 12 de febrero 2006 Fecha de aceptación: 24 de marzo 2006

\footnotetext{
$102 \mathrm{El}$ art. 33 dice: "El condenado mayor de setenta años o el que padezca una enfermedad incurable en período terminal podrá cumplir la pena impuesta en detención domiciliada por resolución...."

103 Corte Nacional de Casación Penal sala I, 14/5/2002, LL 2002-F-444 y Doc. Jud. 2002-3-804; la decisión fue comentada favorablemente por MARTínez DE BACK P., y PLesel DE Kiper, P., Detención domiciliaria. Ley 24.660. Aplicación a procesados no condenados, LL 2003-A-813.

104 Cám. Fed. Crim. y Correc. sala I, 21/12/2000, LL 2001-E-488, con nota aprobatoria de LA RoSA, Mariano, La detención domiciliaria como sustituto de la prisión preventiva; conf. Cám. Fed. San Martín, sala I, 16/7/1998, LL 1998-E-671.

105 Cám. Nac. Crim y Correc. Sala VI, 29/5/1997, ED 175-267; ídem, 10/4/1997, LL 1998-B-4154 (anciano de 77 años que padece enfermedad de Paget, que restringe su capacidad de movimiento y exige atención permanente).

${ }^{106}$ MORELLi (1999) p. 33.
} 


\section{BIBLIOGRAFÍA CITADA}

Barrionuevo De Romero, María Inés (2005): "Ancianidad. Aspectos jurídicos y sicológicos", Actualidad Jurídica, año I, vol. 10.

BobBio, Norberto (1997): "De senectute y otros escritos biográficos" (trad. Esther. BENíTEZ, Madrid, Ed. Taurus).

CADOche, Sara (2002): "Violencia familiar y ancianidad", CADOCHE, Sara, Violencia familiar (Santa Fe, Ed. Rubinzal).

CADOche, Sara (1997): "Violencia hacia los ancianos", en: Revista de Derecho de Familia, $\mathrm{N}^{\circ} 24$.

CARLEO, Liliana Rossi et al. (1997): La terza età nel diritto interno ed internazionale (Napoli, ed. Scientifiche Italiane).

CARrieri, Franceso, Greco, Oronzo, y CATANESI, Roberto (1992): La vecchiaia (Milano, Ed. Giuffrè).

CASADO, María, Consideraciones sobre la atención a la gente grande dependiente (inédito).

CASTÁn, José María (2001): "La tercera edad y el derecho", en: Anales de la Real Academia de Jurisprudencia y legislación de Madrid, $\mathrm{N}^{\circ} 31$.

CheChile A. M. (2005): "El derecho del niño a una adecuada relación con sus abuelos u otros parientes y/o terceros", en: Revista de Derecho de Familia.

Cicerón, Marco Tulio (1946): De la vejez. Obras completas. Vida y discursos (traducc. Manuel De Valbuena, Buenos Aires, Ed. Anaconda) t. II.

CiUro Caldani, Miguel Ángel (1992): "Derecho de la ancianidad", en Investigación y Docencia, $\mathrm{N}^{\circ} 12$.

Ciuro Caldani, Miguel Ángel (2002): "Prólogo", en: Dabove Caramuto, María I., Los derechos de los ancianos (Buenos Aires, Ed. Ciudad Argentina).

Ciuro CALDANi, Miguel Ángel (1995): "Comparación jusfilosófica del derecho de menores y el derecho de la ancianidad", Revista de Investigación y Docencia, $\mathrm{N}^{\circ} 25$.

COlÁs ESCANDÓn, Ana María (2005): Relaciones familiares de los nietos con sus abuelos: derecho de visita, estancia, comunicación y atribución de la guarda y custodia (Madrid, Ed. Thomson-Aranzadi).

Dabove Caramuto, María (1999): "Violencia y ancianidad", Doctrina Judicial, N²: pp. 1165-1171.

Dabove Caramuto, María (2000): "Razones iusfilosóficas para la construcción de un derecho de la ancianidad", Jurisprudencia Argentina, $\mathrm{N}^{\circ}$ 4: pp. 17-23.

Dabove Caramuto, María (1996): "La condición de la mujer anciana desde la perspectiva del derecho", Revista de Bioética y Derecho, $\mathrm{N}^{\circ} 1$ : pp. 49-54.

Dabove Caramuto, María (2000): "Derecho de la ancianidad y bioética en las instituciones geriátricas", Homenaje a Dalmacio Vélez Sársfield, (Córdoba, ed. Academia Nacional de Derecho y Cs. Sociales de Córdoba) t. III.

Dabove Caramuto, María (2002): Los derechos de los ancianos, (Bs. As., ed. Ciudad Argentina).

Dabove Caramuto, María (2005): "Geriátricos en Argentina: complejo punto de encuentro del derecho público y privado”, VV.AA. (coord. HernándeZ, Carlos) El 
Derecho Privado ante la internacionalidad, la integración y la globalización. Homenaje al Prof. Miguel Ángel Ciuro Caldani (Buenos Aires, Ed. La Ley) 684 pp.

DAINO, Miranda Gionfrida (1997): "Tutela dell'anziano e solidarietà familiare. Rapporti tra generazioni”, CARLEO, Liliana Rossi ed altri (a cura di), La terza età nel diritto interno ed internazionale (Napoli, Ed. Scientifiche Italiane).

De Beauvoir, Simone (1989) : La vejez (trad. Aurora Bernárdez, Barcelona, Ed. Edhasa).

De Couto GÁlvez, María (1999): Los problemas legales más frecuentes sobre la tutela, asistencia y protección de personas mayores (Madrid, Ed. Universidad de Comillas).

De Palma, Ángeles (2002): "Respuestas de la administración al envejecimiento de la población”, VV.AA. (coord. Villagrasa AlCaide, Carlos) El envejecimiento de la población y la protección jurídica de las personas mayores (Barcelona, Ed. Cedecs) 308 pp.

DIBÁRBORA, Elisa et al. (2002): "Consentimiento informado, investigación y ancianidad. Algunas consideraciones bioéticas y jurídicas", VV.AA. (coord. SOROKIN, Patricia) Bioética: entre utopias y desarraigos. Libro homenaje a la profesora Gladis Mackinson (Buenos Aires, Ed. Ad Hoc).

Di Tullio BudAssi, Rosana (2003): "El ingreso del anciano al geriátrico", ponencia presentada en XIX Jornadas Nacionales de Derecho Civil, Rosario, t. II.

DogliotTi, Máximo (1991): "Il diritti dell'anziano", VV.AA. (coord. STANZIOne, Pasquale) Anziani e tutele giuridiche (Napoli, ed. Scientifiche Italiane).

ESCRIVÁ, José María (2002): "Aproximación desde el derecho penal: la estafa”, VV.AA. (coord. Villagrasa AlCAIDE, Carlos) El envejecimiento de la población y la protección jurídica de las personas mayores (Barcelona, Ed. Cedecs).

FANZOLATO, Eduardo Ignacio (1996): "Los ancianos y la solidaridad familiar en el siglo XXI", Revista de la Facultad de Derecho y Cs. Sociales de la Universidad Nacional de Córdoba, vol. $4 \mathrm{~N}^{\circ} 2$.

FERrANDO, Gilda (2004): "I diritti degli anziani tra famiglia e istituzioni”, VV.AA. (coord. CENDON, Paolo) Trattato della responsabilità civile e penale in famiglia (Padova, Cedam), t. III.

Frustagli, Sandra, y HernándeZ, Carlos (2005): "Algunas cuestiones contractuales y de daños derivadas de la prestación de servicios geriátricos", Responsabilidad Civil y Seguros, año VIII, $\mathrm{N}^{\circ} 3$.

Ganzanmüller Roig, Carlos y Escudero Moratalla, José Francisco (2005): Discapacidad y derecho (Barcelona, Ed. Bosch).

GARCÍA CANTERO, Gabriel (2004): Las relaciones familiares entre nietos y abuelos (Madrid, Ed. Civitas).

GÓMEZ, Claudio (2003): "Derecho a la igualdad y la discriminación en razón de la edad", La Ley, Suplemento de Derecho Constitucional (17 de junio de 2003).

Rivera, Julio (2003): "Comentario", Revista de Derecho Privado y Comunitario, N 3.

GONEM MACHELlO DE GANDOLFO, Graciela (1996): "Reflexiones sobre la condición de los ancianos en la actualidad", Boletín del Centro de Investigaciones de Filosofía Jurídica y Filosofía social de Rosario, $\mathrm{N}^{\circ} 21$. 
GONEM MaChello De GANDOlfo, Graciela (2003): Los ancianos y el ingreso a una institución geriátrica, ponencia presentada en XIX Jornadas Nacionales de Derecho Civil, Rosario, t. II.

Gonem MACHello De GANDOlfo, Graciela (1999): "Reflexiones sobre la familia, los ancianos y la solidaridad", La Ley, Actualidad (8 de abril de 1999).

Ganzanmüller Roig, Carlos y Escudero Moratalla, José Francisco (2005): Discapacidad y derecho (Barcelona, Ed. Bosch).

HERRENDOrF, Daniel (1998): Los derechos humanos ante la justicia (Buenos. Aires, Ed. A. Perrot).

JiméneZ, Eduardo Pablo (1992): "Los derechos implícitos de la tercera generación. La nueva categoría expansiva en materia de derechos humanos", en: El Derecho, t. 167.

Justo, Alberto: "Los jueces ancianos y la interpretación realista del New Deal", La Ley, Actualidad $\mathrm{N}^{\circ} 6$.

Kemelmajer De CARluCCI, Aída (1997): "El principio de igualdad y el derecho comunitario", en: Anales de la Academia Nacional de Derecho y Cs. Sociales, $\mathrm{N}^{\circ} 35$.

Martínez de Back, P. y Plesel De Kiper, P. (2003): “Detención domiciliaria. Ley 24.660. Aplicación a procesados no condenados", La Ley, A-813.

MARSIGLIA, Miguel Ángel, "Legislación asistencial a la vejez e invalidez", Legislación del trabajo, t. XXVIII-B-1029.

MerCaT-Bruns, Marie (2001): Vieillissement et droit à la lumière du droit français et américain (Paris, Librairie Générale de Droit et de Jurisprudence) 696 pp.

MERINO y HERnÁndeZ, José Luis (2003): "El documento de voluntades anticipadas. Testamento vital", Academia Aragonesa de Jurisprudencia y legislación. Anuario 2002-2003.

MORCILlO, Silvia (2004): "El desamparo legislativo de la ancianidad", Actualidad Juridica de Córdoba. Familia y Minoridad, año I, vol. 8.

Morello, Augusto (2002): "La senectud de cara al derecho", Anales de la Academia Nacional de Derecho y Ciencias Sociales de Bueno Aires, $N^{\circ} 40$.

MORELl, Mariano (1999): "Ética, derecho y ancianidad. Algunas cuestiones vinculadas con el concepto de ancianidad", en: Revista de Bioética y bioderecho, $\mathrm{N}^{\circ} 4$.

Mosset ITURRASPE, Jorge (1995): "El derecho de daños y el ciudadano mayor dependiente", La Ley, A-688.

NERI, Aldo Bonifacio Guido (1990): "La valutazione del danno da menomazione alla persona nell'anziano", Rivista De Dirito Civile, t. II, p. 415.

Pérez, Alonso, Martínez Gallego, Eva María y Reguero Celada, Justo (coord.) (2004): Protección jurídica de los mayores (Madrid, Ed. La Ley).

PitTAMiglio, Carlos (1989): "Tercera edad en la perspectiva de la seguridad social" TSS 1989, p. 482.

POCIELlO, Enrique (2002): "Las pensiones hoy y mañana; un tema a debate", VV.AA. (coord. VillagrasA AlCAIDE, Carlos) El envejecimiento de la población y la protección jurídica de las personas mayores (Barcelona, Ed. Cedecs).

RABBi-BALDi CABANillas, Renato (coord.) (1998): Los derechos individuales ante el interés general. Análisis de casos jurisprudenciales relevantes (Buenos Aires, Ed. Abaco). 
Risolía, Marcos Aurelio "Aspectos jurídicos de la vejez", Anales de la Academia Nacional de Derecho y Ciencias Sociales de Buenos Aires, N²8.

Rivero, María Rosa (2002): "Maltrato hacia los ancianos", VV.AA. (coord. CADOCHE, Sara) Violencia familiar (Santa Fe, Ed. Rubinzal).

Romero, Natalia (2005): "El derecho a la salud nuevamente vulnerado por quienes deben tutelarlo", La Ley, E-314.

Rovira SueIro, María (2005): Relevancia de la voluntad de la persona para afrontar su propia discapacidad (Madrid, Ed. Fundación Aequitas).

Salas Alfaro, Ángel (1999): Derecho de la senectud (México, Ed. Porrúa).

SAMBRIZZI, Eduardo (2005): "Las directivas previas emitidas con la finalidad de rehusar la práctica futura de ciertos actos médicos", La Ley, E-451.

SERRANO García, Ignacio (2004): "Discapacidad e incapacidad en la ley 41/2003 del 18 de Noviembre", Estudios e Derecho Civil. Homenaje al profesor Francisco Javier Serrano García, (Valladolid, Ed. Universidad de Valladolid).

SICA, Salvatore (1991): "Anziani e responsabilità civile: a proposito del concorso di colpa del danneggiato”, VV.AA. (coord. STANZIOne, Pasquale) Anziani e tutele giuridiche (Napoli, ed. Scientifiche Italiane).

STANZIONE, Pasquale (coord.)(1991): Anziani e tutele giuridiche (Napoli, ed. Scientifiche Italiane).

Taiana De Brandi, N., y Llorens, Luis (1996): Disposiciones y estipulaciones para la propia incapacidad (Buenos Aires, Ed. Astrea).

Tomasello, Andrés (2002): Derecho de la ancianidad, en Doc. Jud., 3-937.

Travieso, Juan Antonio (1995): "La protección de los derechos de los ancianos (aspectos nacionales e internacionales)" La Ley Actualidad, boletín del 6/7/1995.

URIARTE, Jorge (1991): "Protección del anciano en nuestro derecho", Derecho de Familia, $\mathrm{N}^{\circ} 5$.

Villagrasa Alcaide, Carlos (coord.)(2002): El envejecimiento de la población y la protección jurídica de las personas mayores (Barcelona, Ed. Cedecs).

Wilde, Zulema (2005a): "Deberes humanos de la familia hacia sus ancianos", Derecho de Familia, $\mathrm{N}^{\circ} 31$.

WILDE, Zulema (2005b): "Las viejas generaciones futuras", Jurisprudencia Argentina, t. III.

WiLDE, Zulema (2005c): "El valor de la autonomía de la voluntad frente a la vejez o a la circunstancia de caer en incapacidad", Anuario Departamentos de Derecho privado, Separata de la revista del notariado, XIX Jornadas Nacionales de Derecho civil.

Zurita Martín, Isabel (2004): Protección civil de la ancianidad (Madrid, Ed. Dykinson-Universidad de Cádiz).

\section{JURISPRUDENCIA CITADA}

Cámara Federal de Apelaciones en lo Criminal y Correccional, sala I, 21 diciembre 2000, La Ley 2001-E-488.

Cámara Federal de Apelaciones de Córdoba, sala A, 24 mayo 2002, La Ley Córdoba 2002-737. 
Cámara Nacional de Apelaciones en lo Civil, sala D, 3 octubre 1995, voto del Dr. Bueres, La Ley 1996-E-1.

Cámara Nacional de Apelaciones en lo Civil, sala G, 5 junio 1995, ED 163-521.

Cámara Nacional de Apelaciones en lo Civil, sala F, 20 agosto 1998, Jurisprudencia Argentina 2000-I-595.

Cámara Nacional de Apelaciones en lo Civil, sala K, 22 mayo 2000, Doc. Jud. 2001-2-413.

Cámara Nacional de Apelaciones en lo Comercial, sala C, 8 marzo 2005, La Ley 2005E-873.

Cámara Nacional de Apelaciones en lo Contencioso Administrativo Federal, sala III, 20 agosto 2003, ED 205-451.

Cámara Nacional de Apelaciones del Trabajo, Sala 2a 10 agosto 1999, en: Jurisprudencia Argentina 1999-IV-24.

Corte Nacional de Casación Penal, sala I, 14 mayo 2002, La Ley 2002-F-444.

Corte Suprema de la Nación, 12 noviembre 2002, La Ley 2003-B-286

Juzgado Federal de Seguridad Social N 7, 17 marzo 2000, Doc. Jud. 2000-3-609.

Suprema Corte de Buenos Aires, 19 febrero 2002, La Ley Bs. As., 2002-1392.

Supremo Tribunal de Jujuy, 3 agosto 1999, La Ley Noroeste, 2000-1209.

Tribunal Contencioso Administrativo de Jujuy, 17 noviembre 2000, La Ley Noroeste 2001-38.

Tribunal Supremo de la ciudad de Bs. As., 29 noviembre 2000, La Ley 2001-B-580. 